\title{
Manejo clínico de la enfermedad por coronavirus SARS-CoV-2
}

\section{Clinical management of the disease SARS-CoV-2 coronavirus}

\begin{abstract}
Franco Eduardo Montufar Andrade, MD¹, Carmelo Dueñas Castell, MD², Oscar Sáenz, MD³,

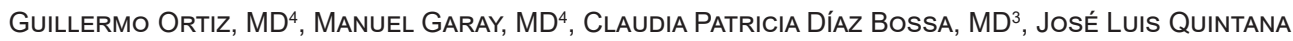
LOBO, MD ${ }^{5}$, FABIO VARÓN-VEGA, MD4, CARLOS MATIZ, MD 3 .
\end{abstract}

\section{Introducción}

Desde diciembre de 2019, en Wuhan, provincia de Hubei (China), se empezaron a describir una serie de casos de infección respiratoria aguda, que rápidamente progresaron a un compromiso respiratorio severo dado por neumonía grave y falla respiratoria aguda, con requerimiento de ingreso a unidades de cuidado intensivo (UCI), sin respuesta adecuada a los tratamientos con antibióticos instaurados y que, eventualmente, desencadenaban la muerte. Los casos iniciales se relacionaron con trabajadores o visitantes de los mercados húmedos o de comida marina de Wuhan, donde hay muchas especies de animales vivos, pero luego se describieron casos en trabajadores de la salud del hospital de $\mathrm{Wu}$ han y en personas que no estuvieron en contacto con estos mercados, pero sí con personas enfermas o que hubiesen visitado dichos sitios (1-7).

Todos los esfuerzos para identificar el agente etiológico, que incluyeron métodos convencionales, pruebas de biología molecular y extracción de material genético, permitieron determinar una nueva especie de coronavirus, diferente a los otros hasta entonces conocidos, pero con gran similitud genética al que ocasionó el síndrome respiratorio agudo severo (SARS) en 2002, en la provincia de Guangdong, China (1-4, 8-11). Para el 07 de enero de 2020, los funcionarios de la salud pública de China confirmaron este hallazgo. Por esta razón, a este nuevo agente causante de este SARS y neumonía se le denominó nuevo coronavirus 2019 (nCoV-2019), pero luego se modificó su nombre a SARS-CoV-2, y a la enfermedad que genera se le denominó enfermedad por coronavirus 2019 (COVID-19) (1, 8-11).

Los coronavirus son virus de ácido ribonucleico (ARN), que circulan a nivel mundial, incluido Colombia, y son los virus que generan un cuadro similar a la gripe o resfriado común. Hay 4 géneros de coronavirus: alfa, beta, delta y gamma, de los cuales, se conoce que los coronavirus alfa y beta son los que infectan a los humanos. Se sabe que 6 especies de coronavirus causan enfermedad en los humanos: 4 son endémicos (HCoV 229E, NL63, OC43 y HKU1), y ocasionan entre $10 \%$ al $30 \%$ de las infecciones respiratorias agudas superiores en adultos; las otras dos especies de coronavirus que generan enfer-
'Internista Neumólogo; Infectólogo.

${ }^{2}$ Neumólogo Intensivista.

${ }^{3}$ Internista Neumólogo.

${ }^{4}$ Internista Neumólogo; Intensivista.

${ }^{5}$ Médico Radiólogo.

Comité de Neumonía Nosocomial y Adquirida en Comunidad, Asociación Colombiana de Neumología y Cirugía de Tórax

Autor de correspondencia:

Franco Eduardo Montufar, MD.

Correo electrónico:

frmontufar@yahoo.com

Recibido: 25/04/2020

Aceptado: 10/05/2020 
medad en humanos, con compromiso de vías respiratorias inferiores y con características epidémicas por su alta transmisibilidad, además de origen zoonótico, son SARS-CoV y MERS-CoV (11).

Los coronavirus tienen la capacidad de infectar animales, especialmente murciélagos, por lo que se sugiere que estos son el reservorio principal. Pueden pasar a otros animales como huéspedes intermediarios o transitorios, en los cuales se piensa que ocurren cambios genéticos o recombinaciones, y desde donde pueden pasar a los humanos y ocasionar enfermedades respiratorias graves, con ello se convierten en una antropozoonosis.

Así, el SARS-CoV pasó de murciélagos a un mamífero llamado civeta, mientras que, en 2012, en Arabia Saudita, oriente medio, el MERS-CoV pasó de los camellos a los seres humanos, lo que generó un cuadro respiratorio severo con alta mortalidad. El SARS-CoV-2, causante de la nueva epidemia, parece tener también un origen zoonótico. El coronavirus de murciélagos infectó y se adaptó a un mamífero silvestre denominado pangolín, desde donde aparentemente ocurrió la transmisión a humanos (Figura 1) (8-10).

Desde el inicio de la epidemia, la Organización Mundial de la Salud (OMS) y los Ministerios o Servi- cios de Salud de los diferentes países han generado el tipo de medidas a implementar en las diferentes etapas, así como reportes diarios sobre el número de casos diagnosticados, recuperados y muertos, para tener análisis dinámicos del comportamiento epidémico. El personal médico y equipos de investigación hacen todos sus esfuerzos para entender el comportamiento epidemiológico y fisiopatológico para instaurar medidas de prevención y control, así como también las posibilidades terapéuticas (12-16). El 30 de enero 2020, tras confirmar 7818 casos en el mundo, la mayoría en China, la OMS declaró "emergencia de salud pública de importancia internacional". La rápida progresión de la enfermedad obligó a la OMS a declarar al COVID-19 como pandemia el 11 de marzo 2020. Para entonces, el número de casos confirmados era 119319 en 113 países/territorios. Para esa fecha, Italia y España se convierten en los países con más casos reportados fuera de China, y la fuente de los primeros casos en Latinoamérica (6).

En los sistemas de salud a nivel mundial es de vital importancia que podamos identificar a los pacientes que podrían haber estado expuestos y que tienen signos o síntomas relacionados con la infección por SARS-CoV-2, para tomar las medidas de salud pública pertinentes. En general, y a través del tiempo transcurrido de la pandemia, siguen siendo válidos los siguientes aspectos:

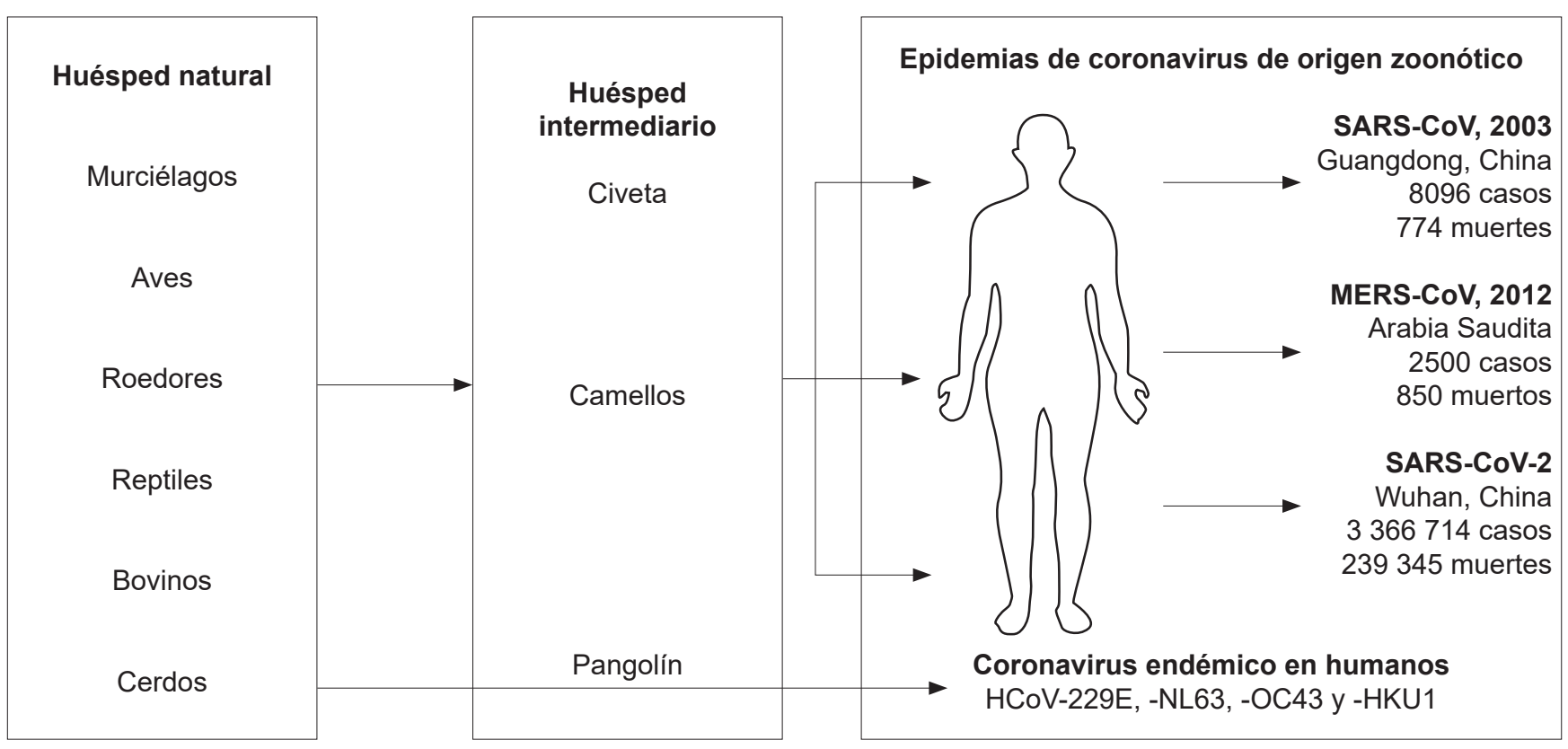

Figura 1. Huéspedes y transmisión de coronavirus. 
- Historia detallada de viajes o residencia en áreas donde haya transmisión comunitaria.

- Presencia de fiebre persistente y síntomas respiratorios asociados, así como manifestaciones extrapulmonares.

- Aislar a los pacientes sospechosos y confirmados.

- Medidas universales para evitar el contagio, como distanciamiento físico, higiene de manos y de tos, y uso de mascarilla.

- Informar a las instancias de salud pública pertinentes (en nuestro país la Secretaria de Salud, direcciones seccionales de salud, Instituto Nacional de Salud y el Ministerio de Salud y Protección Social) (16-20).

Los criterios para realizar una evaluación clínica, investigación epidemiológica y pruebas para $\mathrm{CO}$ VID-19 se basan en las definiciones de caso adoptadas por la OMS, que varían de país a país, y con el paso del tiempo y la progresión de los casos y cambios de la pandemia. Para más información remitimos al lector a las páginas web de la OMS y del Ministerio de Salud de Colombia (5). Los datos de circulación viral, número de casos y mortalidad se actualizan cada día, y se deben consultar en los enlaces respectivos $(6,7)$.

\section{Características clínicas}

Las manifestaciones clínicas pueden ser muy variadas, a pesar de su predilección por el tracto respiratorio. En más del 80\% de los casos, el cuadro es leve, con síntomas respiratorios menores de la vía aérea superior, malestar general, odinofagia y cefalea, entre otros, sin mayores complicaciones y autolimitado (10$12,15-25)$.

En 14\%-15\% de los pacientes hay síntomas moderados, con manifestaciones variadas de un amplio espectro de enfermedad, que lleva a hospitalización, esto incluye neumonía, la cual obliga al manejo hospitalario para garantizar las medidas de soporte generales, oxigenoterapia, vigilancia y tratamiento. Un pequeño porcentaje ( $1 \%-4 \%)$ es de los pacientes considerados graves y críticos, que requieren ingreso en UCI y, eventualmente, medidas de soporte adicionales, como ventilación mecánica, vasoactivos, terapia de reem- plazo renal y membrana de oxigenación extracorpórea (ECMO), entre otras; la mortalidad en estos pacientes se acerca al $47 \%$.

El tiempo de incubación estimado es de 5,2 días (intervalo de confianza [IC 95\%] 4,1-7,0); pero se considera que los síntomas podrían presentarse entre 2 a 14 días después de la infección $(5,9,10,16,18)$. Se estima que la duración de la enfermedad dura en promedio 5,8 días (IC 95\% 4,3-7,5), y el tiempo medio desde el inicio de la enfermedad a la admisión al hospital es de 12,5 días (IC 95\% 10,3-14,8).

Debemos tener en cuenta que un alto porcentaje de los pacientes (40\%-45\%) puede estar en fase presintomática o ser asintomáticos, y si se pierden las medidas de precaución universales, estos son las principales fuentes de contagio. Las manifestaciones clínicas más importante, descritas en los diferentes trabajos publicados sobre COVID-19, se pueden observar en la Tabla 1.

Tabla 1. Síntomas frecuentes de COVID-19

\begin{tabular}{|lc|}
\hline \multicolumn{1}{|c}{ Síntomas } & Porcentaje \\
\hline Fiebre & $43-98$ \\
\hline Tos & $56-82$ \\
\hline Respiración corta & $24-31$ \\
\hline Disnea & $3-64$ \\
\hline Cefalea & $4,9-34$ \\
Síntomas del tracto respiratorio & $5-24$ \\
superior & $7,3-15$ \\
Mialgias & $5-14$ \\
Odinofagia & $1-10$ \\
Náuseas/vómitos & $3-8$ \\
\hline Diarrea & $30-60$ \\
\hline Anosmia-disgeusia & \\
\hline
\end{tabular}

Con base en las manifestaciones clínicas, severidad de la enfermedad, y con el fin de poder establecer pautas de tratamiento y sitio de atención, el consenso de expertos de China clasificó la enfermedad por SARS-CoV-2 en leve, moderada, severa y crítica (26). Sin embargo, esta clasificación deja por fuera algunos grupos clínicos, por tal razón, se considera la posibilidad de adoptar la clasificación propuesta en la Tabla 2.

Revista Colombiana de Neumología Vol. 32 N. ${ }^{\circ} 1$ | 2020 
Tabla 2. Clasificación clínica del COVID-19 y tratamientos a instaurar

\begin{tabular}{|c|c|c|c|c|c|}
\hline \multicolumn{6}{|c|}{ Presentaciones clínicas } \\
\hline Severidad & $\begin{array}{c}\text { Características } \\
\text { clínicas }\end{array}$ & Conducta & $\begin{array}{l}\text { Sitio de } \\
\text { atención }\end{array}$ & $\begin{array}{l}\text { Tratamiento } \\
\text { farmacológico }\end{array}$ & $\begin{array}{l}\text { Tratamiento no } \\
\text { farmacológico }\end{array}$ \\
\hline Asintomático & $\begin{array}{l}\text { Paciente libre de } \\
\text { síntomas, pero con } \\
\text { contacto estrecho } \\
\text { con caso positivo o } \\
\text { confirmado }\end{array}$ & $\begin{array}{l}\text { - Aislamiento } \\
\text { domiciliario } \\
\text { - Habitación } \\
\text { individual } \\
\text { - Uso de mascarilla } \\
\text { convencional todo } \\
\text { el tiempo posible } \\
\text { - Ante la presencia } \\
\text { de síntomas de } \\
\text { alarma (disnea, } \\
\text { fiebre persistente) } \\
\text { consulta a } \\
\text { Urgencias }\end{array}$ & $\begin{array}{l}\text { Manejo } \\
\text { ambulatorio en } \\
\text { casa }\end{array}$ & Ninguno & $\begin{array}{l}\text { - Educación } \\
\text { - Higiene de } \\
\text { manos } \\
\text { - Higiene de la tos } \\
\text { - Aislamiento } \\
\text { social } \\
\text { - Seguimiento } \\
\text { telefónico por la } \\
\text { entidad a cargo, } \\
\text { para orientacio- } \\
\text { nes y determinar } \\
\text { los síntomas de } \\
\text { alarma }\end{array}$ \\
\hline $\begin{array}{l}\text { Sintomático } \\
\text { sin neumonía } \\
\text { y sin comor- } \\
\text { bilidad }\end{array}$ & $\begin{array}{l}\text { - Saturación >94\% } \\
\text { - Fiebre } \\
\text { - Tos } \\
\text { - Síntomas } \\
\text { respiratorios altos } \\
\text { - Sin disnea }\end{array}$ & $\begin{array}{l}\text { - Examen clínico } \\
\text { - Oximetría de pulso } \\
\text { - Aislamiento } \\
\text { domiciliario } \\
\text { - Habitación individual } \\
\text { - Uso de mascarilla } \\
\text { convencional, todo } \\
\text { el tiempo posible } \\
\text { - Ante la presencia de } \\
\text { síntomas de alarma } \\
\text { (disnea, fiebre per- } \\
\text { sistente) consultar a } \\
\text { Urgencias }\end{array}$ & $\begin{array}{l}\text { Manejo } \\
\text { ambulatorio en } \\
\text { casa }\end{array}$ & $\begin{array}{l}\text { Acetaminofén, si } \\
\text { hay fiebre }\end{array}$ & $\begin{array}{l}\text { - Educación } \\
\text { - Higiene de } \\
\text { manos } \\
\text { - Higiene de la } \\
\text { tos } \\
\text { - Aislamiento } \\
\text { social } \\
\text { - Seguimiento } \\
\text { telefónico por } \\
\text { entidad a cargo, } \\
\text { para determinar } \\
\text { síntomas de } \\
\text { alarma }\end{array}$ \\
\hline $\begin{array}{l}\text { Sintomático } \\
\text { sin neumonía } \\
\text { y con } \\
\text { comorbilidad, } \\
\text { con o sin } \\
\text { disnea }\end{array}$ & $\begin{array}{l}\text { - Saturación menor } \\
\text { de } 93 \% \\
\text { - Con o sin fiebre } \\
\text { - Síntomas } \\
\text { respiratorios: tos, } \\
\text { expectoración, } \\
\text { disnea, síntomas } \\
\text { respiratorios altos }\end{array}$ & $\begin{array}{l}\text { - Examen clínico } \\
\text { - Oximetría de pulso } \\
\text { - Radiografía de } \\
\text { tórax PA y lateral } \\
\text { - Paraclínicos: } \\
\text { hemoleucograma, } \\
\text { función renal } \\
\text { y hepática, } \\
\text { troponina, LDH, } \\
\text { dímero D, gases } \\
\text { arteriales }\end{array}$ & $\begin{array}{l}\text { Manejo hos- } \\
\text { pitalario en } \\
\text { salas fuera } \\
\text { de UCI/UCE } \\
\text { por 3-5 días, } \\
\text { para evaluar } \\
\text { la presencia } \\
\text { de síntomas } \\
\text { de alarma y } \\
\text { definir alta o } \\
\text { continuar hos- } \\
\text { pitalización } \\
\text { Paraclínicos } \\
\text { de control } \\
\text { cada } 48 \text { horas } \\
\text { Evaluar los } \\
\text { parámetros de } \\
\text { falla ventilato- } \\
\text { ria, para definir } \\
\text { el traslado a } \\
\text { UCl }\end{array}$ & $\begin{array}{l}\text { - Medidas gene- } \\
\text { rales: } \\
\text { - Manejo de la fiebre } \\
\text { - Hidratación } \\
\text { - Protección gástrica } \\
\text { - Tromboprofilaxis } \\
\text { - Sin nebulizaciones } \\
\text { - Si se requiere el } \\
\text { uso de bronco- } \\
\text { dilatadores se } \\
\text { deben usar inha- } \\
\text { ladores, en dosis } \\
\text { medida } \\
\text { - Se debe usar es- } \\
\text { teroides en toda } \\
\text { comorbilidad que } \\
\text { los requiera } \\
\text { Además de las } \\
\text { medidas anteriores: } \\
\text { oxigenoterapia } \\
\text { y manejo para } \\
\text { COVID-19 }\end{array}$ & $\begin{array}{l}\text { - Habitación } \\
\text { individual } \\
\text { - Uso adecuado } \\
\text { de los EPP } \\
\text { por el personal } \\
\text { asistencial } \\
\text { - Medidas de } \\
\text { precaución } \\
\text { especiales: } \\
\text { aislamiento } \\
\text { de contacto y } \\
\text { gotas } \\
\text { - Higiene de } \\
\text { manos } \\
\text { - Higiene de la } \\
\text { tos }\end{array}$ \\
\hline
\end{tabular}


Tabla 2. Clasificación clínica del COVID-19 y tratamientos a instaurar (continuación)

\begin{tabular}{|c|c|c|c|c|c|}
\hline \multicolumn{6}{|c|}{ Presentaciones clínicas } \\
\hline Severidad & $\begin{array}{c}\text { Características } \\
\text { clínicas }\end{array}$ & Conducta & $\begin{array}{l}\text { Sitio de } \\
\text { atención }\end{array}$ & $\begin{array}{l}\text { Tratamiento } \\
\text { farmacológico }\end{array}$ & $\begin{array}{l}\text { Tratamiento no } \\
\text { farmacológico }\end{array}$ \\
\hline $\begin{array}{l}\text { Neumonía } \\
\text { leve }\end{array}$ & $\begin{array}{l}\text { - Saturación } \leq 93 \\
\text { - Fiebre, tos } \\
\text { - Síntomas } \\
\text { respiratorios } \\
\text { - Radiografía } \\
\text { de tórax con } \\
\text { infiltrados } \\
\text { pulmonares } \\
\text { - CRB-65; o CURB- } \\
65 \leq 2\end{array}$ & $\begin{array}{l}\text { - Examen clínico } \\
\text { - Oximetría de pulso } \\
\text { Imágenes: } \\
\text { radiografía de } \\
\text { tórax PA y lateral; } \\
\text { considerar TAC } \\
\text { de tórax, si hay } \\
\text { desaturación y } \\
\text { la radiografía de } \\
\text { tórax es normal } \\
\text { Microbiológicos: } \\
\text { PCR COVID-19 } \\
\text { más PCR múltiple } \\
\text { para patógenos } \\
\text { respiratorios } \\
\text { (FilmArray) o } \\
\text { panel de virus } \\
\text { respiratorios } \\
\text { Otros estudios en } \\
\text { busca de etología: } \\
\text { hemocultivos } \\
\text { Paraclínicos: } \\
\text { hemoleucograma, } \\
\text { PCR, función } \\
\text { renal y hepática, } \\
\text { troponina, LDH, } \\
\text { dímero D, ferritina, } \\
\text { gases arteriales, } \\
\text { electrocardiograma } \\
\text { - Tratamiento para } \\
\text { COVID-19 }\end{array}$ & $\begin{array}{l}\text { - Manejo } \\
\text { hospitalario en } \\
\text { sala fuera de } \\
\text { UCI/UCE } \\
\text { - Evaluar la } \\
\text { presencia } \\
\text { de síntomas } \\
\text { de alarma } \\
\text { y definir el } \\
\text { traslado a } \\
\text { UCI, según los } \\
\text { criterios ATS/ } \\
\text { IDSA }\end{array}$ & $\begin{array}{l}\text { - Medidas } \\
\text { generales: } \\
\text { Manejo de la } \\
\text { fiebre } \\
\text { - Hidratación } \\
\text { - Protección } \\
\text { gástrica } \\
\text { - Tromboprofilaxis } \\
\text { - Sin } \\
\text { nebulizaciones } \\
\text { - Si se requiere } \\
\text { el uso de } \\
\text { broncodilatadores } \\
\text { se deben usar } \\
\text { inhaladores en } \\
\text { dosis medida } \\
\text { - Se debe usar } \\
\text { esteroides en } \\
\text { toda comorbilidad } \\
\text { que los requiera } \\
\text { - Además de } \\
\text { las medidas } \\
\text { anteriores: } \\
\text { Oxigenoterapia } \\
\text { Manejo para } \\
\text { COVID-19 } \\
\text { Manejo de NAC } \\
\text { en salas de } \\
\text { hospitalización } \\
\text { fuera de UCI, } \\
\text { según las guías }\end{array}$ & $\begin{array}{l}\text { - Habitación } \\
\text { individual } \\
\text { - Uso adecuado } \\
\text { de los EPP } \\
\text { para el personal } \\
\text { asistencial } \\
\text { - Medidas de } \\
\text { precaución } \\
\text { especiales: } \\
\text { aislamiento } \\
\text { de contacto y } \\
\text { gotas } \\
\text { - Higiene de } \\
\text { manos } \\
\text { - Higiene de la } \\
\text { tos } \\
\text { Medidas de } \\
\text { precaución por } \\
\text { aerosoles ante } \\
\text { situaciones que } \\
\text { los genere }\end{array}$ \\
\hline
\end{tabular}


Tabla 2. Clasificación clínica del COVID-19 y tratamientos a instaurar (continuación)

\begin{tabular}{|c|c|c|c|c|c|}
\hline \multicolumn{6}{|c|}{ Presentaciones clínicas } \\
\hline Severidad & $\begin{array}{c}\text { Características } \\
\text { clínicas }\end{array}$ & Conducta & $\begin{array}{l}\text { Sitio de } \\
\text { atención }\end{array}$ & $\begin{array}{c}\text { Tratamiento } \\
\text { farmacológico }\end{array}$ & $\begin{array}{l}\text { Tratamiento no } \\
\text { farmacológico }\end{array}$ \\
\hline Severo & $\begin{array}{ll}\text { - } & \text { Disnea, } \mathrm{FR} \geq 30 \\
\text { - } & \text { Saturación } \leq 93 \% \\
\text { - } & \mathrm{PaO}_{2} / \mathrm{FiO}_{2}<300 \\
\text { - } & \text { Infiltrados } \\
& \text { pulmonares } \\
& \text { multilobares } \\
\text { - } & \mathrm{CRB}-65 \text { o CURB } \\
& 652\end{array}$ & $\begin{array}{l}\text { - Examen clínico } \\
\text { - Oximetría de pulso } \\
\text { radiogenes: } \\
\text { tórax PA y lateral; } \\
\text { considerar TAC } \\
\text { de tórax si hay } \\
\text { desaturación y } \\
\text { radiografía de } \\
\text { tórax normal } \\
\text { - Microbiológicos: } \\
\text { PCR COVID-19; } \\
\text { PCR múltiple } \\
\text { para patógenos } \\
\text { respiratorios } \\
\text { (FilmArray) o } \\
\text { panel de virus } \\
\text { respiratorios } \\
\text { Otros estudios en } \\
\text { busca de etología: } \\
\text { hemocultivos } \\
\text { - Paraclínicos: } \\
\text { hemoleucograma, } \\
\text { PCR, función } \\
\text { renal y hepática, } \\
\text { troponina, LDH, } \\
\text { dímero D, ferritina, } \\
\text { interleucina-6, } \\
\text { gases arteriales, } \\
\text { electrocardiograma } \\
\text { Tratamiento para } \\
\text { COVID-19 }\end{array}$ & $\begin{array}{l}\text { Manejo en } \\
\text { hospitalización } \\
\text { fuera de UCI y } \\
\text { monitorización } \\
\text { continua de } \\
\text { criterios ATS/ } \\
\text { IDSA, para } \\
\text { definir ingreso } \\
\text { a UCI }\end{array}$ & $\begin{array}{l}\text { - Medidas } \\
\text { generales: } \\
\text { - Manejo de la } \\
\text { fiebre } \\
\text { - Hidratación } \\
\text { - Protección } \\
\text { gástrica } \\
\text { - Tromboprofilaxis } \\
\text { - Sin } \\
\text { nebulizaciones } \\
\text { Si se requiere } \\
\text { el uso de } \\
\text { broncodilatadores } \\
\text { se deben usar } \\
\text { inhaladores con } \\
\text { dosis medida } \\
\text { - Se debe usar } \\
\text { esteroides en } \\
\text { toda comorbilidad } \\
\text { que los requiera } \\
\text { Además de las } \\
\text { medidas anteriores: } \\
\text { - Oxigenoterapia } \\
\text { - Manejo para } \\
\text { COVID-19 } \\
\text { - Manejo de } \\
\text { NAC grave, } \\
\text { según las guías, } \\
\text { incluir manejo } \\
\text { con oseltamivir } \\
\text { hasta descartar } \\
\text { influenza, y } \\
\text { manejo de } \\
\text { macrólido } \\
\text { (azitromicina o } \\
\text { claritromicina) }\end{array}$ & $\begin{array}{l}\text { - Habitación } \\
\text { individual } \\
\text { - Uso adecuado } \\
\text { de los EPP } \\
\text { para el personal } \\
\text { asistencial } \\
\text { - Medidas de } \\
\text { precaución } \\
\text { especiales: } \\
\text { aislamiento } \\
\text { de contacto y } \\
\text { gotas } \\
\text { - Higiene de } \\
\text { manos } \\
\text { - Higiene de la } \\
\text { tos } \\
\text { Medidas de } \\
\text { precaución por } \\
\text { aerosoles ante } \\
\text { situaciones que } \\
\text { los generen }\end{array}$ \\
\hline
\end{tabular}


Tabla 2. Clasificación clínica del COVID-19 y tratamientos a instaurar (continuación)

\begin{tabular}{|c|c|c|c|c|c|}
\hline \multicolumn{6}{|c|}{ Presentaciones clínicas } \\
\hline Severidad & $\begin{array}{c}\text { Características } \\
\text { clínicas }\end{array}$ & Conducta & $\begin{array}{c}\text { Sitio de } \\
\text { atención }\end{array}$ & $\begin{array}{c}\text { Tratamiento } \\
\text { farmacológico }\end{array}$ & $\begin{array}{l}\text { Tratamiento no } \\
\text { farmacológico }\end{array}$ \\
\hline Crítico & $\begin{array}{l}\text { - CRB-65 o CURB- } \\
653 \text { o } 4 \\
\text { - Criterios ATS/ } \\
\text { IDSA de ingreso } \\
\text { a UCI: } 1 \text { criterio } \\
\text { mayor o } 2 \\
\text { criterios menores } \\
\text { - Insuficiencia } \\
\text { respiratoria } \\
\text { - Choque séptico } \\
\text { o disfunción o } \\
\text { falla de múltiples } \\
\text { órganos }\end{array}$ & $\begin{array}{l}\text { - Examen clínico } \\
\text { - Oximetría de pulso } \\
\text { radígenes: } \\
\text { róragrafía de } \\
\text { considerar TAC lateral; } \\
\text { de tórax si hay } \\
\text { desaturación y } \\
\text { radiografía de } \\
\text { tórax normal } \\
\text { - Microbiológicos: } \\
\text { PCR COVID-19; } \\
\text { PCR múltiple } \\
\text { para patógenos } \\
\text { respiratorios } \\
\text { (FilmArray) o } \\
\text { panel de virus } \\
\text { respiratorios } \\
\text { - Otros estudios en } \\
\text { busca de etología: } \\
\text { hemocultivos } \\
\text { Paraclínicos: } \\
\text { hemoleucograma, } \\
\text { PCR, función } \\
\text { renal y hepática, } \\
\text { troponina, LDH, } \\
\text { dímero D, ferritina, } \\
\text { interleucina-6, } \\
\text { gases arteriales, } \\
\text { electrocardiograma }\end{array}$ & $\begin{array}{l}\text { Cuidado } \\
\text { intensivo }\end{array}$ & $\begin{array}{l}\text { Medidas generales: } \\
\text { - Manejo de la } \\
\text { fiebre } \\
\text { - Hidratación } \\
\text { - Protección } \\
\text { gástrica } \\
\text { - Tromboprofilaxis } \\
\text { - Sin } \\
\text { nebulizaciones } \\
\text { - Si se requiere } \\
\text { el uso de } \\
\text { broncodilatadores } \\
\text { se deben usar } \\
\text { inhaladores en } \\
\text { dosis medida } \\
\text { - Se debe usar } \\
\text { esteroides en } \\
\text { toda comorbilidad } \\
\text { que los requiera } \\
\text { Además de las } \\
\text { medidas anteriores: } \\
\text { - Oxigenoterapia } \\
\text { o ventilación } \\
\text { mecánica } \\
\text { Manejo para } \\
\text { COVID-19 } \\
\text { Manejo de } \\
\text { NAC grave, } \\
\text { según las guias; } \\
\text { incluir manejo } \\
\text { con oseltamivir } \\
\text { hasta descartar } \\
\text { influenza, y } \\
\text { de macrólido } \\
\text { (azitromicina o } \\
\text { claritromicina) }\end{array}$ & $\begin{array}{l}\text { - Manejo en } \\
\text { UCl: ventila- } \\
\text { ción mecáni- } \\
\text { ca, soporte } \\
\text { vaso activo, } \\
\text { TRR, seda- } \\
\text { ción, ECMO } \\
\text { y todos los } \\
\text { requerimien- } \\
\text { tos de manejo } \\
\text { en UCl } \\
\text { - Habitación } \\
\text { individual } \\
\text { - Uso adecua- } \\
\text { do de los EPP } \\
\text { para el perso- } \\
\text { nal asistencial } \\
\text { - Medidas de } \\
\text { precaución } \\
\text { especiales: } \\
\text { aislamiento } \\
\text { de contacto y } \\
\text { gotas } \\
\text { Higiene de } \\
\text { manos } \\
\text { Higiene de la } \\
\text { tos } \\
\text { Medidas de } \\
\text { precaución } \\
\text { por aerosoles } \\
\text { ante situacio- } \\
\text { nes que los } \\
\text { generen }\end{array}$ \\
\hline \multicolumn{6}{|c|}{$\begin{array}{l}\text { Duración del aislamiento: en la mayoría, el aislamiento o cuarentena se puede retirar después de } 10 \text { días del inicio de } \\
\text { síntomas y de que tenga resolución de la fiebre de al menos } 24 \text { horas sin uso de medicamentos. Se considera mínima } \\
\text { infectividad después del día 10. Para personas que no desarrollan síntomas, el aislamiento se puede retirar después } \\
\text { de } 10 \text { días de la fecha de la prueba positiva. Para personas gravemente enfermas o inmunosuprimidas se debe usar la } \\
\text { estrategia basada en PCR; para los otros casos no se recomienda realizar nuevas pruebas. }\end{array}$} \\
\hline
\end{tabular}


Tabla 2. Clasificación clínica del COVID-19 y

tratamientos a instaurar (continuación)

\section{Presentaciones clínicas}

\section{Manejo de COVID-19 (manejo solo hospitalario, bajo estricta supervisión médica e idealmente bajo protocolos establecidos)}

\section{Elección}

- Dexametasona: $6 \mathrm{mg} /$ día por 10 días en pacientes que requieran oxígeno o ventilación mecánica y más de 7 días de evolución de síntomas. Si no hay dexametasona se deben dar dosis equivalentes de esteroides, como metilprednisolona $32 \mathrm{mg} / \mathrm{día}$, hidrocortisona $80 \mathrm{mg} / \mathrm{cada} 12$ horas o prednisolona $40 \mathrm{mg} / \mathrm{día}$ por vía oral

- Siempre que se administre esteroides deberá darse ivermectina en dosis única de $200 \mu \mathrm{g} / \mathrm{kg}$, para profilaxis de infección por Strongyloides stercoralis y posible síndrome de hiperinfestación y migración larvaria

- Tocilizumab: dosis de $8 \mathrm{mg} / \mathrm{kg}$ (dosis máxima de $800 \mathrm{mg}$ ) IV, máximo 2 dosis, con intervalo de 12 horas. Indicado en todos los pacientes que fallaron en el uso de esteroides o tienen contraindicaciones para su uso o cumplan los siguientes criterios:

- Mas de 7 días de evolución de síntomas, con deterioro respiratorio progresivo y requerimiento de VM o requerimiento de aumento de parámetros de VM

- Niveles de interleucina $6>40 \mathrm{pg} / \mathrm{mL}$ o, alternativamente, dímero D >1500 $\mu \mathrm{g} / \mathrm{L}$

- Dos de los tres siguientes criterios PCR >100 mg/L o >50 mg/L, si el valor se duplicó en menos de 48 horas, LDH $>250 \mathrm{UI} / \mathrm{mL}$ y recuento absoluto de linfocitos $<600$

- Todo paciente que tenga comorbilidad y requiera ventilación mecánica, así no tenga infiltrados pulmonares, debe recibir manejo para COVID-19

\section{Alternativa}

- Remdesivir: dosis de carga de 200 mg y 100 mg/día IV desde el día 2 al 10

- Uso de esteroides por otras indicaciones, como crisis de asma, agudización de EPOC, choque con uso de vasoactivo u otras indicaciones justificadas de esteroide por otras causas. Se deben usar sin restricción

- Plasma convaleciente: 2 dosis de $200 \mathrm{~mL}$ de plasma convaleciente, derivado de donantes recientemente recuperados y con títulos de anticuerpos neutralizantes $\geq 1: 640$

\section{Anticoagulación}

- No utilizar terapia anticoagulante de rutina en pacientes con COVID-19 graves

- Realizar anticoagulación profiláctica en pacientes con COVID-19 graves

- En pacientes con alto riesgo de trombosis se sugiere usar anticoagulación, con monitorización estrecha del riesgo y beneficio

\section{Tratamientos no recomendados}

- Lopinavir/ritonavir

- Cloroquina o hidroxicloroquina

- Azitromicina

Nota: para usar dexametasona o esteroides equivalentes de COVID-19 se debe descartar influenza y, además, administrar ivermectina

\section{Manejo de NAC en las salas de hospitalización fuera de $\mathrm{UCl}$, según las guías institucionales o nacionales}

Manejo de NAC grave en UCl o fuera de ella

Manejo para NAC grave con antibióticos, según las guías institucionales o nacionales más manejo de la influenza H1N1 (se debe mantener un manejo con oseltamivir, hasta descartar la influenza 
Tabla 2. Clasificación clínica del COVID-19 y

tratamientos a instaurar (continuación)

\section{Presentaciones clínicas}

Factores de riesgo o mal pronóstico en COVID-19

- Hemoleucograma: linfocitos $<1000$, neutrófilos $>10000$, plaquetas $<150000$

- $\mathrm{LDH}>250 \mathrm{UI} / \mathrm{L}$

- PCR elevada $>10 \mathrm{mg} / \mathrm{dL}$ o $100 \mathrm{mg} / \mathrm{L}$

- Dímero $D>1 \mathrm{mg} / \mathrm{mL}$

- Ferritina $>1200$

- Elevación de bilirrubinas (bilirrubina total), aminotransferasas

- Elevación de azoados

- Troponina elevada

\section{Comorbilidades de mal pronóstico}

Hipertensión arterial, diabetes mellitus, enfermedad coronaria o cardiopatías, EPOC, asma, obesidad y enfermedades neoplásicas

\section{Criterios para definir el alta}

- Estabilidad clínica por 72 horas

- Temperatura $<37,8^{\circ} \mathrm{C} ; \mathrm{FC}<100$; FR $<24$; PAS $>90 \mathrm{~mm} \mathrm{Hg}$ por más de 8 horas

- Ausencia de compromiso sistémico de la enfermedad

- Comorbilidades estables

- Tolerancia a la vía oral

- Sin evidencia de trastorno cognitivo

- Solo requerimiento de oxígeno domiciliario, en algunos casos.

ATS: American Thoracic Society; ECMO: membrana de oxigenación extracorpórea; EPOC: enfermedad pulmonar obstructiva crónica; EPP: elementos de protección personal; $\mathrm{FC}$ : frecuencia cardíaca; $\mathrm{FiO}_{2}$ : fracción inspirada de oxígeno; FR: frecuencia respiratoria; IDSA: Infectious Diseases Society of America; LDH: lactato deshidrogenasa; NAC: neumonía adquirida en la comunidad; PA: posteroanterior; $\mathrm{PaO}_{2}$ : presión arterial de oxígeno; PAS: presión arterial sistólica; PCR: proteína Creactiva; TAC: tomografía axial computarizada; UCE: Unidad de Cuidados Especiales; UCI: Unidad de Cuidados Intensivos; VM: ventilación mecánica.

\section{Factores de mal pronóstico}

Hasta el momento se reconocen algunas características o condiciones del paciente que se asocian con mal pronóstico (20-25):

- La presencia de comorbilidades se asocia con mal pronóstico. En los pacientes con peores desenlaces, al menos una comorbilidad está presente $(23,7 \%$ al $48 \%$ ), con cociente de riesgo (HR) de 3,9. En la medida que la enfermedad es más severa, la presencia de comorbilidad es más frecuente: enfermedad crítica $67,1 \%$, enfermedad severa $46,3 \%$ y enfermedad moderada $37,8 \%$.

- Las principales comorbilidades observadas son, en orden de frecuencia, hipertensión arterial $(35,7 \%$ en críticos frente a $20,7 \%$ en moderados), enfermedad pulmonar obstructiva crónica (EPOC) $(15,7 \%$ en críticos frente a $4,6 \%$ en moderados), tabaquismo $14 \%$, diabetes mellitus $10,3 \%$, enfermedad cardiovascular y coronaria $8 \%$ y neoplasia $2,5 \%$.

- La edad es otro factor de riesgo de mal pronóstico, a mayor edad, mayor es el riesgo; a partir de los 60 años, el pronóstico es peor, y este es un factor de riesgo (razón de momios [OR] 8,5; IC 95\% 1,6-44,8).

- En todos los pacientes con sospecha o confirmación de COVID-19 debemos realizar exámenes, que nos brinden información sobre la severidad del proceso inflamatorio, compromiso de otros órganos, y que se han considerado como factores de mal pronóstico: 
- Hemograma con leucopenia, especialmente, linfopenia $<1000$.

- Lactato deshidrogenasa (LDH) $>250 \mathrm{U} / \mathrm{L}$ (HR $2,5)$, si el nivel es mayor, el riesgo de mal pronóstico aumenta, LDH >500 (HR 9,8).

- Dímero D >1000 $\mu \mathrm{g} / \mathrm{L}$.

- Troponina elevada.

- $\quad$ PCR $>10 \mathrm{mg} / \mathrm{dL}$ o $>100 \mathrm{mg} / \mathrm{L}$ o $>50 \mathrm{mg} / \mathrm{L}$, si el valor se duplicó en menos de 48 horas.

- Aspartato amino transferasa/alanino amino transferasa $($ AST/ALT $)>40$.

- Ferritina $>1200$.

Las escalas de predicción de severidad de la enfermedad, como la CURB-65 (Tabla 3), y los criterios de la American Thoracic Society y la Infectious Diseases Society of America (ATS/IDSA) (Tabla 4), para definir el sitio de atención y de ingreso a cuidado intensivo, se vienen implementado para evaluar la severidad y el manejo de los pacientes con COVID-19 (Figura 2).

Recientemente se publicó otra escala para definir la progresión de la enfermedad, llamada Comorbidity, Age, Lymphocytes, LDH score (CALL), que incluye como parámetros la presencia de comorbilidad, edad, linfopenia y LDH (21). Puntuaciones $\geq 6$ tienen un valor predictivo positivo (VPP) 50,7\% y un valor predictivo negativo (VPN) $98,5 \%$. Se ha visto que, de acuerdo con el incremento de puntuación, el riesgo de progresión a cuadros más severos es mayor: CALL 4-6 riesgo de progresión $<10 \%$; CALL 7-9 10\%-40\%; y CALL $10-13$ progresión $>50 \%$. La escala Sequential Organ Failure Assessment (SOFA) $>2$ o Quick SOFA (q-SOFA) >1 también se ha encontrado como un factor de mal pronóstico en los análisis multivariados (16).

Las complicaciones más frecuentes observadas en los pacientes severos o críticos son arritmias (44\%), cardiomiopatía (33\%), infección sobreagregada (31\%), lesión cardíaca aguda (30\%), choque (20\%), síndrome de dificultad respiratoria aguda (SDRA) (17\%- 29\%), lesión renal aguda (8\%-23\%) y muerte (41\%).
Las imágenes del tórax también pueden ser consideradas como de apoyo en el pronóstico del paciente. Recientemente se ha considerado que el compromiso multilobar en vidrio esmerilado periférico, que puede estar presente entre el 51,6\% y 96,2\%, pudiese ser también un factor de mal pronóstico (19-21).

\section{Pruebas diagnósticas}

Para establecer el diagnóstico, investigadores chinos publicaron la secuencia completa del genoma de SARSCoV-2 el 10 de enero de 2020. Luego, los Centers for Disease Control and Prevention (CDC) desarrollaron una prueba rápida de reacción en cadena de la polimerasa en tiempo real (RT-PCR), que puede diagnosticar la presencia del virus en muestras respiratorias.

El 24 de enero, los CDC publicaron el protocolo de ensayo para esta prueba (disponible en: https://www. cdc.gov/coronavirus/2019-nCoV/lab/index.html). Esta prueba, inicialmente limitada a laboratorios de los CDC, está ya en uso en diferentes laboratorios certificados a nivel mundial, con el fin de poder establecer un diagnóstico confirmatorio de los casos.

En el paciente con sospecha de infección por SARSCoV2 debemos, en primera instancia, realizar una historia clínica exhaustiva, que nos permita identificar el nexo epidemiológico y catalogarlo como caso sospechoso, de acuerdo con las definiciones epidemiológicas, a esto se debe sumar el juicio y las características clínicas. La RTPCR tiene una sensibilidad del $80 \%$ y especificidad del $99 \%$. Si la primera prueba es negativa, y es un paciente con alta sospecha clínica y epidemiológica, esta se debe repetir en 48 horas. La positividad de la prueba empieza a descender en la medida que transcurre el tiempo, desde el inicio de los síntomas; después del día 10 se considera casi nula la posibilidad de ser infectante, excepto en pacientes graves o con inmunosupresión.

Se piensa que las pruebas serológicas pueden tener alguna validez después del día 10, estas nos permiten la detección de anticuerpos inmunoglobulina $\mathrm{M}$ e inmunoglobulina G IgM/IgG. Cerca del 40\%-50\% de los pacientes desarrolla respuesta de anticuerpos contra infección por SARS-CoV-2 a los 7 días, y la mayoría a los 14 días de la infección $(2,4,12,15-17)$. 
Tabla 3. Escala CRB-65 o CURB -65

\begin{tabular}{|c|c|c|c|}
\hline Sigla & \multicolumn{3}{|c|}{ Parámetros } \\
\hline C & \multicolumn{3}{|c|}{ Confusión, desorientación o prueba mental abreviada $\leq 8$} \\
\hline $\mathbf{U}$ & \multicolumn{3}{|c|}{ Urea $>7 \mathrm{mmol} / \mathrm{L}($ urea $=$ BUN $\times 2,14)$} \\
\hline $\mathbf{R}$ & \multicolumn{3}{|l|}{$\mathrm{FR} \geq 30$} \\
\hline B & \multicolumn{3}{|c|}{ Presión arterial sistólica $<90$ mm Hg o diastólica $<60$ mm Hg } \\
\hline 65 & \multicolumn{3}{|l|}{ Edad $\geq 65$ años } \\
\hline \multicolumn{4}{|c|}{ La puntuación de cada parámetro es 0 si está ausente, y 1 si está presente } \\
\hline \multicolumn{4}{|c|}{ La escala CRB-65 no incluye la urea. Esta podría ser útil en los servicios de Urgencias y Triaje } \\
\hline $\begin{array}{l}\text { Puntuación CRB-65 o } \\
\text { CURB-65 }\end{array}$ & $\%$ mortalidad & Riesgo & Sitio de manejo \\
\hline 0 & $0,67 \%$ & Grupo I: bajo riesgo & Ambulatorio \\
\hline 1 & $2,7 \%$ & & \\
\hline 2 & $6,8 \%$ & Grupo II & $\begin{array}{l}\text { Ambulatorio supervisado o manejo hospitalario de } \\
\text { corto tiempo }\end{array}$ \\
\hline 3 & $14 \%$ & Grupo III: alto riesgo & Neumonía severa. Hospitalización en UCI \\
\hline $4 \circ 5$ & $27,8 \%$ & & \\
\hline
\end{tabular}

BUN: nitrógeno ureico en sangre; FR: frecuencia respiratoria.

Tabla 4. Criterios ATS/IDSA para ingreso a UCI

\begin{tabular}{|c|c|}
\hline Criterios mayores & Criterios menores \\
\hline Necesidad de ventilación mecánica & $\mathrm{FR}>30$ \\
\hline Choque, requerimiento de soporte vasoactivo & $\begin{array}{l}\mathrm{PaO}_{2} / \mathrm{FiO}_{2}<250 \\
\text { Compromiso multilobar } \\
\text { Confusión } \\
\mathrm{BUN}>20 \mathrm{mg} / \mathrm{dL} \\
\text { Leucopenia }<4000 \mathrm{cel} / \mathrm{mL} \\
\text { Trombocitopenia }<100000 \mathrm{cel} / \mathrm{mL} \\
\text { Hipotermia }<36^{\circ} \mathrm{C} \\
\text { Hipotensión que requiere alto aporte de líquidos }\end{array}$ \\
\hline
\end{tabular}

BUN: nitrógeno ureico en sangre; $\mathrm{FR}$ : frecuencia respiratoria. $\mathrm{FiO}_{2}$ : fracción inspirada de oxígeno; $\mathrm{PaO}_{2}$ : presión arterial de oxígeno. 

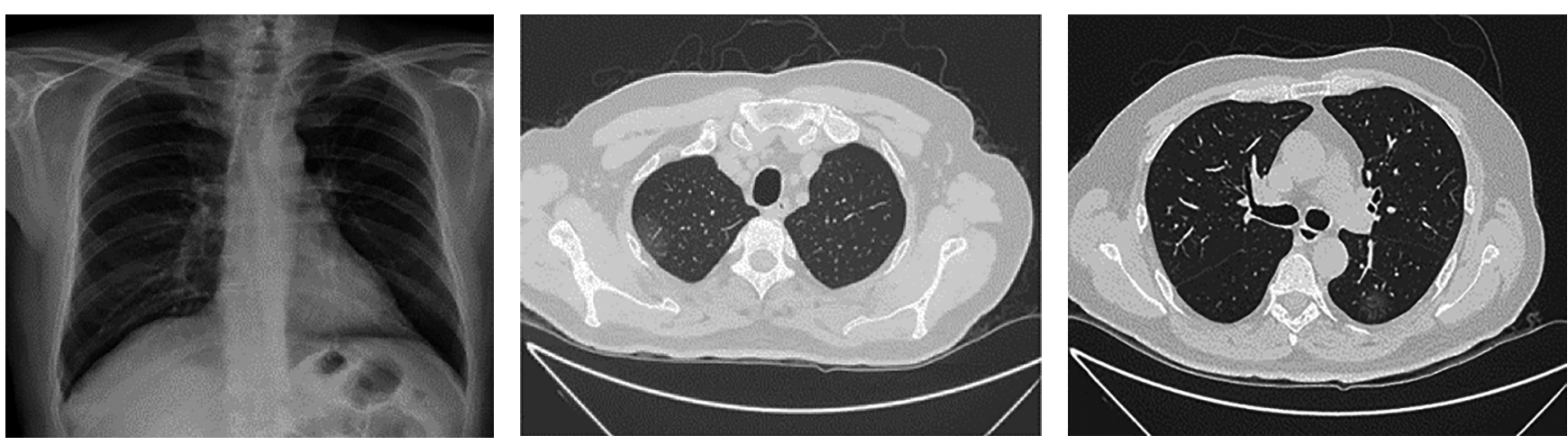

Figura 2. Radiografía de tórax normal con tomografía patológica. Paciente de 62 años con 3 días de evolución de tos seca, fiebre y astenia, Radiografía normal, con discrepancia clínica radiológica. La TC evidenció opacidades subpleurales en vidrio esmerilado (patrón clásico). Luego, RT-PCR confirmó SARS-CoV-2.

Siempre que sospechemos una infección por SARS$\mathrm{CoV}-2$ debemos realizar estudios adicionales en busca de otros patógenos del tracto respiratorio, como son las pruebas de biología molecular de PCR múltiple, o también la detección por antígenos, que nos orientan sobre la posibilidad de otro tipo de infecciones que expliquen el cuadro, coinfecciones o sobreinfecciones (19).

\section{Características radiográficas}

La radiografía del tórax, y especialmente la tomografía computada (TC) de alta resolución, son ayudas diagnósticas relevantes en el diagnóstico, clasificación y manejo de la enfermedad por SARS-CoV-2. Estas nos ayudan a identificar los posibles estadios de la enfermedad y a considerar potenciales diagnósticos diferenciales y complicaciones asociadas. Sin embargo, cabe la pena mencionar que, durante un episodio de pandemia, la realización de imágenes a un número elevado de pacientes con sospecha o confirmación de COVID-19 es un reto, pues la adherencia a los protocolos de control de infecciones, con el fin de disminuir la transmisión al personal de salud u otros usuarios de imágenes diagnósticas, hace que los estudios puedan ser más demorados de lo usual, a lo que se suma la severidad de la enfermedad.

Si bien la ultrasonografía pudiese ser útil para determinar el compromiso parenquimatoso, la experiencia actual con COVID-19 aun no es la adecuada para generar recomendaciones. La radiografía del tórax tie- ne una baja sensibilidad para detectar alteraciones, especialmente en enfermedad leve o en etapas tempranas de COVID-19; esta puede ser anormal entre el 60\% y $77 \%$ de los casos.

La radiografía de tórax puede ser útil en pacientes con enfermedad severa como aproximación diagnóstica inicial, y no se recomienda en enfermedad leve. Para pacientes hospitalizados en salas, la radiografía de tórax portátil pudiese servir para evaluar la progresión de la enfermedad y disminuir el riesgo de transmisión, lo que evita el desplazamiento hacia las unidades de imágenes diagnósticas. La TC del tórax es más sensible para detectar alteraciones parenquimatosas, complicaciones o diagnósticos diferenciales; sin embargo, tiene el reto del desplazamiento del paciente, tiempo de uso del tomógrafo y riesgo de transmisión de SARS-CoV-2 (26-32).

\section{Indicaciones de las imágenes en COVID-19}

- La indicación se fundamenta en los criterios clínicos, y la información disponible se basa en los datos de los países que han vivido la epidemia antes que nosotros.

- En la mayoría de los algoritmos diagnósticos para COVID-19 se sugiere que, en pacientes con sospecha clínica de infección y severamente enfermos (desaturación, taquipnea), se debe realizar radiografía de tórax como estudio inicial. 
- La tomografía computada (TC) está indicada para:

- Pacientes hospitalizados con alta sospecha clínica.

- Pacientes con otra patología crítica y sospecha o duda diagnóstica de COVID-19.

- Casos particulares de COVID-19, en los que el equipo médico a cargo así lo considere.

- No se considera la realización de estudios por imagen de control de forma rutinaria.

- En los casos particulares en los que se requieran estudios de seguimiento, estos deben realizarse con equipo portátil; solo en casos excepcionales, en los que el equipo médico a cargo así lo considere, se puede realizar TC de control.

- En nuestro medio, la ecografía de tórax puede ser una alternativa práctica en el diagnóstico o seguimiento de los casos, si existen los recursos técnicos y el personal entrenado.

\section{Hallazgos por imagen en la infección por COVID-19}

- Los hallazgos por imagen en la infección por COVID-19 no son específicos y siempre deben interpretarse dentro del contexto clínico.

- En ningún caso, los estudios por imagen establecen un diagnóstico etiológico, o pueden sugerir o no la presencia de neumonía viral, la cual, en un contexto clínico y epidemiológico apropiado, podría sugerir COVID-19. Los hallazgos por imagen dependen del estadio de la enfermedad.

- Los hallazgos en radiografías son inespecíficos, y un alto porcentaje de pacientes no presenta hallazgos, como:

- Ocupación alveolar en parches y áreas de consolidación de predominio basal y periférico, los cuales son los más frecuentes.

- Otros hallazgos sugestivos, como opacidades focales tenues, patrón intersticial focal o difuso y la combinación de patrón alvéolo-intersticial.
- Se considera que las adenopatías, el derrame pleural o los nódulos son lesiones no sugestivas de COVID-19.

- Se han propuesto 4 patrones para caracterizar los hallazgos en TC para el diagnóstico de infección por COVID-19; estos son:

- Patrón clásico: opacidades multifocales en vidrio esmerilado de predominio periférico, patrón de empedrado, patrón en halo reverso y otros hallazgos de patrón de neumonía de organización.

- Patrón indeterminado: vidrio esmerilado difuso, perihiliar o unilateral, con o sin consolidación.

- Patrón atípico: es en el que no se describen los hallazgos de patrón clásico o indeterminado, y en el que se sugieren diagnósticos alternativos, como la presencia de consolidación lobar, cavitación, nódulos, árbol en gemación, adenopatías o derrame pleural.

- Patrón no neumonía: hallazgos que no incluyen consolidación ni patrón en vidrio esmerilado.

- Los hallazgos en imágenes se describen más frecuentemente como bilaterales, de distribución periférica, con compromiso posterior y multilobar.

En las Figuras 2-5 podemos observar algunos ejemplos de pacientes con las características mencionadas.

\section{Recomendaciones sobre las imágenes (20-22, 27-32)}

- Los estudios por imagen se indican en pacientes sospechosos o con diagnóstico de COVID-19, y manifestaciones clínicas moderadas o severas de la enfermedad, como hipoxemia o disnea moderada a severa.

- Los estudios por imagen no están indicados en pacientes sospechosos o con diagnóstico de COVID-19 con manifestaciones clínicas leves, a menos que haya riesgos de progresión de la enfermedad (pacientes mayores de 60 y comorbilidades, como enfermedad cardiovascular, diabetes mellitus, enfermedad pulmonar crónica, hipertensión arterial, inmunocompromiso de cualquier etiología). 

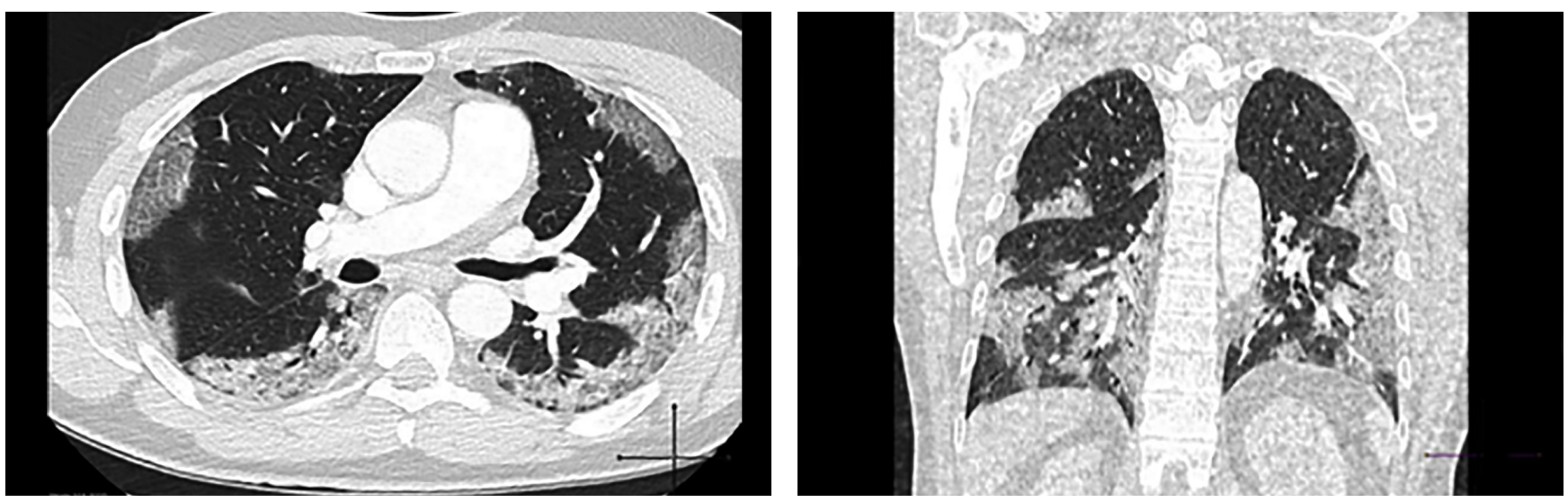

Figura 3. Compromiso multilobar periférico: patrón clásico. Paciente de 57 años, con clínica de tos seca, fiebre, leucocitosis e insuficiencia respiratoria hipoxémica. La TC evidencia opacidades subpleurales multilobares, con tendencia a la consolidación. La reconstrucción coronal confirma la localización subpleural, de predominio en lóbulos inferiores.
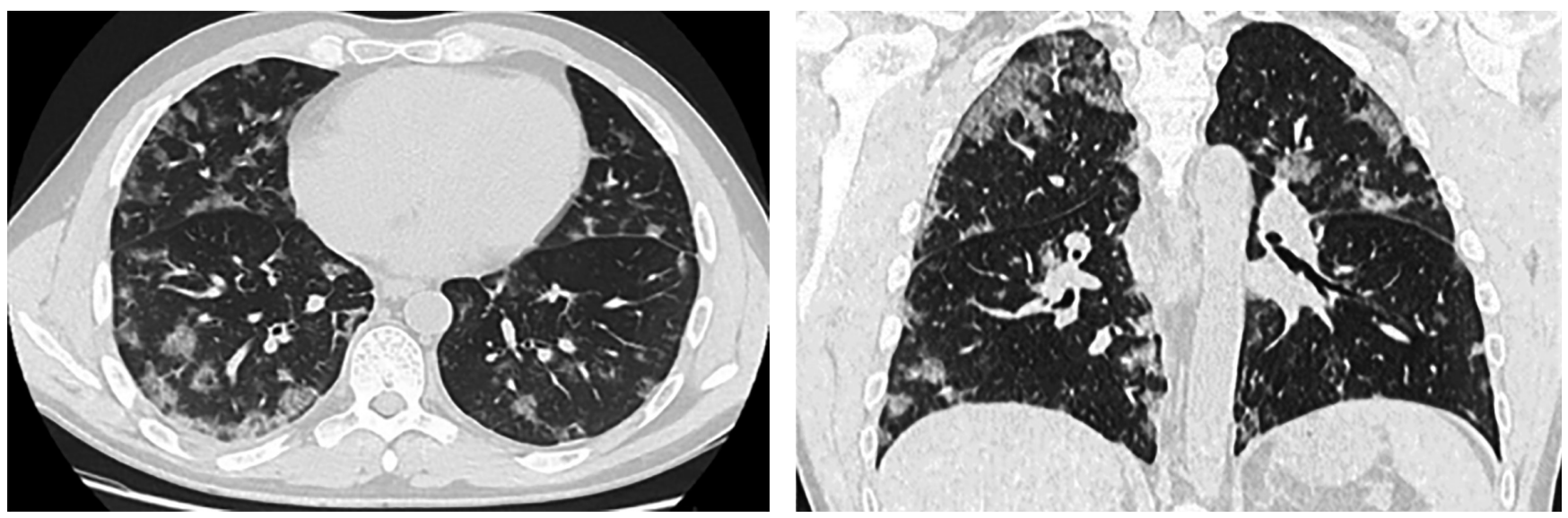

Figura 4. Vidrio esmerilado difuso: patrón clásico. Paciente de 45 años, con cuadro clínico de tos seca, fiebre, leucocitosis e insuficiencia respiratoria hipoxémica. TC con múltiples áreas de aumento en la densidad del parénquima pulmonar, con patrón de vidrio esmerilado y distribución en parches; además, se aprecia patrón de halo reverso. La reconstrucción coronal evidencia opacidades en vidrio esmerilado y patrón de empedrado de predominio subpleural y apical.
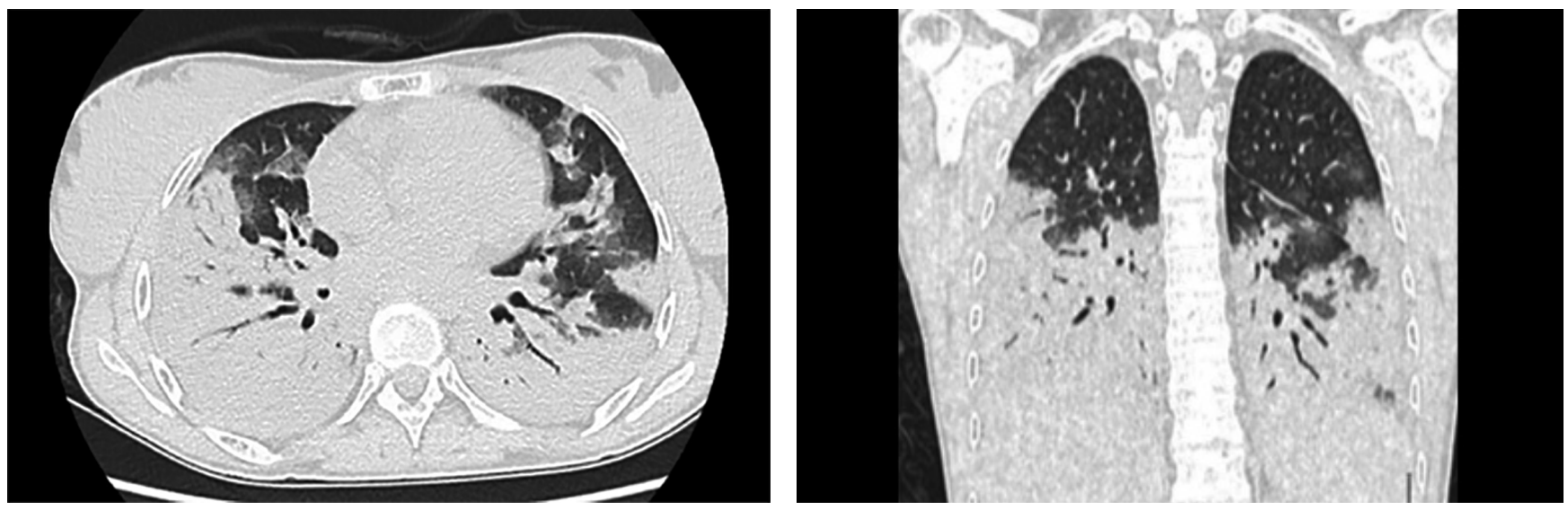

Figura 5. Patrón indeterminado. Paciente de 32 años, con cuadro clínico de tos seca, fiebre e insuficiencia respiratoria hipoxémica. Prueba positiva para COVID-19. TC con áreas de consolidación multilobar de predominio basal.

22 Revista Colombiana de Neumología Vol. 32 N. ${ }^{\circ} 1 \mid 2020$ 
- Se recomienda reservar la TC para pacientes sospechosos o con diagnóstico de COVID-19 y deterioro clínico.

- La TC está indicada en pacientes que presentan hipoxemia luego de la recuperación de COVID-19.

- En pacientes con hallazgos incidentales en TC sugestivos de neumonía viral se indica realizar pruebas de laboratorio para COVID-19.

- Se proponen 4 patrones para la caracterización de los hallazgos tomográficos, estos siempre se deben analizar en un contexto clínico, e idealmente discutir con el equipo multidisciplinar a cargo del paciente.

\section{Medidas de prevención}

Las medidas de prevención universales están enfocadas en evitar el contagio y la rápida expansión; debemos impartir educación en higiene de manos, cuantas veces sea posible, higiene de la tos, evitar el contacto estrecho con personas enfermas o sospechosas, distanciamiento físico mayor de 2 metros, aislamiento social, comportamiento saludable en viajes y hacer uso adecuado de la mascarilla quirúrgica o tapabocas en todo momento, inclusive a pesar de mantener el distanciamiento físico.

En las instituciones prestadoras de servicios de salud, además de las medidas universales mencionadas anteriormente, debemos educar y adherirnos a los protocolos para el uso de elementos de protección personal (EPP), uso de mascarilla quirúrgica y protección ocular (gafas/protector facial) en todo momento durante la permanencia en la institución, medidas de precauciones estándar y especiales por gotas y contacto en el manejo de todo paciente sospechoso o confirmado con COVID-19, además de medidas de precaución por aerosoles en todas las situaciones o procedimientos donde se generen aerosoles. Todo paciente y acompañante que asista a instituciones de salud deberá portar mascarilla, también será obligatorio el uso de la misma para todo paciente institucionalizado. Asimismo, debemos estar preparados para una toma adecuada de muestras y uso de EPP adecuados cuando realicemos dicha recolección $(1-5,8,12-15,19)$.
Las normas de etiqueta de la tos que todos debemos poner en práctica para proteger a otros de enfermar son medidas sencillas, que vale la pena recordarlas:

- Al toser o estornudar cubra su boca y nariz con la cara interna de su codo o con un pañuelo desechable.

- Deseche el pañuelo inmediatamente.

- Siempre realice lavado de manos con agua y jabón, o higiene de manos con alcohol glicerinado, después de estornudar o toser o de cuidar a otras personas enfermas.

- Evite el contacto estrecho con otras personas cuando tenga con tos y fiebre (no saludar de beso en la mejilla, no saludo de manos, no abrazos).

- Si usa mascarilla asegúrese que le cubra la boca y nariz. Evite tocar la mascarilla con las manos una vez se la haya colocado, deseche las mascarilla (recuerde que es de un solo uso y no la puede cargar en su bolsillo después de usarla), realice higiene de manos después de quitarse la mascarilla.

Los diferentes organismos internacionales han considerado que los pacientes sospechosos o casos confirmados deben permanecer en cuarentena; término acuñado desde hace varios años al aislamiento de pacientes con enfermedades transmisibles, acorde con el período de incubación; en el caso de COVID-19, el tiempo de cuarentena es de 14 días. A raíz de esto se tienen disposiciones de cuarentena con inmigrantes y no inmigrantes considerados casos sospechosos (15).

\section{Tratamiento}

- Medidas de soporte: las medidas de soporte son el eje del tratamiento.

- Paciente ambulatorio: paciente con enfermedad leve, que requiere seguimiento en casa y monitorización de signos y situaciones de alarma, para definir la hospitalización. Requiere manejo sintomático, solo acetaminofén, para la fiebre o dolor. No usar antibióticos y poner en práctica las medidas recomendadas de higiene de manos y de la tos, distanciamiento físico y aislamiento social. 
- Paciente hospitalizado: el paciente cursa con enfermedad que requiere hospitalización por severidad del compromiso, comorbilidades y factores de mal pronóstico. Debe estar en una habitación individual, con medidas de aislamiento por gotas y contacto, asegurar adecuada hidratación e ingesta alimentaria, suplencia de oxígeno pertinente acorde a su condición clínica, protección gástrica, tromboprofilaxis y monitorización continua para definir cambios con respecto a los requerimientos de soportes más avanzados, como ventilación mecánica invasiva y soporte vasoactivo (33-35). En caso de requerir ventilación mecánica, esta debe ser protectora, con bajos volúmenes corrientes $(4-8 \mathrm{~mL} / \mathrm{kg})$ y presiones meseta $\leq 30 \mathrm{~mm} \mathrm{H}_{2} \mathrm{O}$, y un nivel de presión positiva al final de la espiración (PEEP) ajustado a la mecánica pulmonar. La ECMO se debe considerar en pacientes con hipoxemia refractaria, que dificulta la ventilación mecánica protectora en centros de referencia.

\section{Tratamientos específicos}

No hay tratamientos específicos para el COVID-19. La evidencia disponibles se basa en los reportes y series de casos, cohortes retrospectivas y reportes preliminares de ensayos clínicos. Estamos aprendiendo de las experiencias de los países que han afrontado esta epidemia antes que nosotros (35-38).

\section{Lopinavir/ritonavir (LPVr)}

Es un inhibidor de proteasa utilizado ampliamente en el manejo de pacientes con virus de la inmunodeficiencia humana (VIH) y síndrome de inmunodeficiencia adquirida (SIDA), y con algunos datos de experiencia en epidemias previas por SARS. Sin embargo, en los ensayos clínicos asignados al azar en curso de tratamientos para COVID-19 (RECOVERY trials), en junio 29, los investigadores analizaron los datos y suspendieron el reclutamiento, dado que el uso de LPVr no demostró beneficio en pacientes hospitalizados. En este estudio, un total de 1596 pacientes se reclutaron al grupo de LPVr y se compararon con 3376 asignados solo a cuidado usual. Este no demostró tener un efecto en la mortalidad a 28 días (RR 1,04; IC 95\% 0,91-1,118), y los hallazgos fueron consistentes en los diferentes grupos. Tampoco demostró beneficio en la reducción de la necesidad de ventilación mecánica, ni en la duración de la estancia hospitalaria; por tanto, no se recomienda en el manejo de COVID-19 (36).

\section{Recomendación LPVr}

No se recomienda en el manejo de COVID-19.

\section{Hidroxicloroquina o cloroquina}

Estudios observacionales iniciales mostraron que estos medicamentos podrían tener alguna utilidad en algunos casos asociados con antivirales, como lopinavir/ritonavir, o con antibióticos, como azitromicina, y que al utilizarse en etapas tempranas podrían lograr disminuir la mortalidad. Se ha planteado que la cloroquina o hidroxicloroquina tienen efecto benéfico in vitro en la reducción de la replicación y la carga viral, más aún cuando se adiciona azitromicina.

En la experiencia clínica de pacientes tratados con hidroxicloroquina más azitromicina se logró una respuesta favorable en el $81,3 \%$ de los casos, con un rápido descenso de la carga viral en aspirados nasofaríngeos y negatividad de la PCR en $93 \%$ al día 8 (37). Sin embargo, el estudio fue muy cuestionado por el número de pacientes y el diseño metodológico, lo que llevó a una retractación del mismo.

Una reciente revisión sistemática resumió la evidencia al respecto (38). Esta incluyó 6 publicaciones, de muy limitada calidad metodológica (una carta, un estudio in vitro, una editorial, un consenso de expertos y dos guías nacionales) y 23 estudios clínicos en curso en China. Los autores encontraron que la cloroquina era efectiva en limitar la replicación del SARS-CoV-2 in vitro. Con ello, los autores concluyeron que hay evidencia racional, efectividad preclínica, así como evidencia de seguridad en el uso clínico a largo plazo para otras indicaciones, y para justificar investigaciones clínicas en COVID-19. Sin embargo, el uso clínico debería adherirse al marco de referencia de intervenciones no registradas y a la monitorización de uso de emergencia (MEURI) o ser éticamente aprobados como un estudio por la OMS.

Un reciente estudio clínico asignado al azar en paralelo, de fase IIb, incluyó a 81 pacientes (41 con altas 
dosis y 40 con bajas dosis de cloroquina) hospitalizados con infección por COVID-19 entre marzo 23 y el 05 de abril de 2020, en un centro de atención terciario en Manaos, Brasil. La letalidad al día 13 fue de 39\% en el grupo de dosis altas, y $15 \%$ en el grupo de dosis bajas. El grupo de dosis altas presentó más frecuencia de intervalo QTc mayor de 500 milisegundos $(18,9 \%)$ comparado con el de dosis bajas $(11,1 \%)$. Por ello sugieren que no deberían recomendarse las altas dosis de cloroquina para el tratamiento de COVID-19, especialmente en pacientes que además reciben azitromicina y oseltamivir, debido al riesgo de prolongar el QTc y al incremento de la letalidad (39).

En los ensayos clínicos asignados al azar en curso de tratamientos para COVID-19 (RECOVERY trials) se analizaron los datos de pacientes aleatorizados con hidroxicloroquina, comparado con cuidado usual solo (1561 pacientes frente a 3155). No se observaron diferencias significativas en la mortalidad a 28 días (26,8\% frente a $25 \%$ ), con RD 1,09 ; IC $95 \% 0,96-$ $1,23, P=0,18$; los datos fueron consistentes en todos los subgrupos. Los pacientes asignados al brazo de hidroxicloroquina tuvieron menos probabilidad de egresar vivos al día 28 (60,3\% frente a 62,8\%) (RR $0,92$; IC $95 \% 0,85-0,99)$ y estuvo asociado con incremento de la estancia hospitalaria y con el riesgo de progresión a ventilación mecánica invasiva o muerte; por tanto, no se recomienda el uso de hidroxicloroquina en el manejo de COVID-19 (40).

\section{Recomendaciones de hidroxicloroquina o cloroquina}

No se recomienda el uso de hidroxicloroquina o cloroquina como tratamiento para COVID-19.

\section{Remdesivir (RDV)}

El RDV es un fosforamidato profármaco, análogo nucleótido 1'-cyano-substituido, cuya forma trifosfato (RDV-TP) se asemeja al ATP, y se usa como sustrato de ARN de polimerasas virales. Tiene amplio espectro antiviral in vitro e in vivo contra $\mathrm{ARN}$ virus, que incluye a las familias Filoviridae (como el virus del ébola (EBOV), Paramyxoviridae (como el virus Nipah (NiV) y Pneumoviridae (como del virus sincitial respiratorio (RSV).
La actividad contra el coronavirus, que incluye SARS-CoV y MERS-CoV, también se ha demostrado in vitro y en modelos animales. Se han realizado varias descripciones observacionales sobre el uso de RDV; sin embargo, recientemente se publicó el informe preliminar de un ensayo clínico doble ciego y controlado con placebo, en el cual se asignaron al azar 1063 pacientes: 538 con RDV y 521 con placebo. La dosis utilizada de RDV fue de $200 \mathrm{mg} / \mathrm{IV}$, como dosis de carga, seguidos por $100 \mathrm{mg}$ /día IV, desde el día 2 al 10 . Los datos indicaron que los pacientes del grupo RDV tuvieron un tiempo medio de recuperación de 11 días (IC 95\% 9-12) frente a 15 días del grupo placebo (IC 95\% 13-19), con un RR de recuperación de 1,32; IC $95 \% 1,12-1,55 ; P<0,001$. La mortalidad a 14 días fue de $7,1 \%$ para RDV frente a $11,9 \%$ para placebo, con HR de muerte de 0,7; IC 95\% 0,47-1,04). El porcentaje de eventos adversos serios fue de $21 \%$ para RDV y de $27 \%$ para placebo, siendo RDV superior al placebo en pacientes hospitalizados con COVID-19, tanto en la recuperación como en el impacto en mortalidad.

Esto genera grandes expectativas en el tratamiento específico antiviral para SARS-CoV-2, y ha motivado a que agencias internacionales, como la Food and Drug Administration (FDA), estén adelantando intervenciones para tener disponibilidad del medicamento. Sin embargo, más estudios son pertinentes y a la fecha no hay disponibilidad del medicamento (41).

\section{Tocilizumab}

En la patogénesis de la enfermedad severa o crítica por COVID-19 se ha demostrado que puede ocurrir una respuesta inflamatoria severa, denominada tormenta de citocinas mediada por liberación de citocinas proinflamatorias. En esta se ha demostrado niveles elevados de IL-6, IL-2, IL-7, IL-10, factor estimulante de colonias granulocitos-monocitos (GM-CSF), proteína inducible por interferón gamma (IP10), proteína quimioatrayente de monocitos (MPC1), proteína inflamatoria de macrófagos 1 alfa (MIP1A) y factor de necrosis tumoral alfa (TNF $\alpha)$. Pareciera ser que el GM-CSF e IL-6 son la clave en esta tormenta de citocinas, que genera daño alveolocapilar, alteración del intercambio gaseoso, especialmente en la difusión de oxígeno, y eventualmente fibrosis pulmonar y falla orgánica. Esta es la razón 
de considerar que los anticuerpos monoclonales contra el receptor de IL-6 (receptor de membrana mIL6R y receptor soluble (sIL-6R), como el tocilizumab, que se une a este receptor, inhibe la traducción de las señales y bloquea la respuesta inflamatoria (42).

Los estudios iniciales en pocos pacientes con COVID-19 severa o crítica evidenciaron que en las primeras 24 horas la fiebre desaparecía, y en los primeros 5 días había mejoría notable del componente inflamatorio, expresado por una disminución de requerimiento de oxígeno en el 75\% y de los infiltrados pulmonares en el TC en $90 \%$ de los casos, así como cambios en el recuento de linfocitos, con retorno a su nivel normal en el 52,6\% de los casos, y descenso de la PCR de manera significativa (84,2\%), con disminución de la mortalidad (42).

Uno de los estudios más recientes evalió el uso de tocilizumab en pacientes con neumonía severa por COVID-19 (TESEO), donde se incluyeron pacientes $\geq 18$ años con COVID-19 confirmado por PCR, que cumplieran alguno de los siguientes criterios: frecuencia respiratoria $(\mathrm{FR})>30$, hipoxemia (saturación $<93 \%$ al aire ambiente o presión arterial de oxígeno/fracción inspirada de oxígeno $\left[\mathrm{PaO}_{2} / \mathrm{FiO}_{2}\right]<300$ al aire ambiente o descenso de la $\mathrm{PaO}_{2} / \mathrm{FiO}_{2}$ en más del $30 \%$ en 24 horas), e infiltrados pulmonares con progresión en más del 50\% en 24\%-48\%. En el estudio se compararon 365 pacientes con cuidado estándar por 14 días, de acuerdo con la guía local (incluye oxígeno, hidroxicloroquina, azitromicina, lopinavir/ ritonavir o darunavir/cobicistat), frente a 179 pacientes con cuidado estándar más tocilizumab $[8 \mathrm{mg} / \mathrm{kg} /$ IV (máximo $800 \mathrm{mg}$ ) en 2 dosis, con intervalo de 12 horas, o $162 \mathrm{mg}$ por vía subcutánea en 2 dosis simultaneas (324 en total)]). Se evidenció que la administración de tocilizumab puede reducir el riesgo de ventilación mecánica o muerte, con HR 0,61; IC 95\% $0,4-0,92 ; p=0,020$. Sin embargo, en los pacientes con tocilizumab se diagnosticó un número mayor de nuevas infecciones, $13 \%$ frente a $4 \%(p<0,001)(43)$.

\section{Recomendación tocilizumab}

Se sugiere el uso de tocilizumab en pacientes que no respondieron a esteroides o tienen contraindicación para su uso, y en quienes se cumplan todos los siguientes criterios:
- Más de 7 días de evolución de los síntomas.

- Deterioro respiratorio evidenciado por disminución en los índices de oxigenación (descenso de $\mathrm{PaO}_{2} /$ $\mathrm{FiO}_{2}$ en más del $30 \%$ en 24 horas), requerimiento de soporte ventilatorio o aumento en el requerimiento de los parámetros ventilatorios y progresión de infiltrados en más del $50 \%$ en $24-48$ horas.

- Niveles de IL-6 $>40$ pg/mL o dímero D mayores de 1500 .

- 2 de 3 de los siguientes:

- $\quad$ PCR $>100 \mathrm{mg} / \mathrm{L}$ o $>50 \mathrm{mg} / \mathrm{L}$, si su valor se duplicó en las últimas 48 horas.

- $\quad \mathrm{LDH}>250 \mathrm{UI} / \mathrm{mL}$.

- Recuento absoluto de linfocitos $<600 \mathrm{cel} / \mathrm{mm}^{3}$.

- Haber descartado otros posibles focos de infección.

\section{Anticoagulantes en COVID-19}

Estudios recientes describieron que la enfermedad grave por COVID-19 es comúnmente por coagulación intravascular diseminada (CID), la cual puede existir en la mayoría de las muertes $(16,18,44)$. La disfunción de las células endoteliales inducida produce un exceso de generación de trombina y disminución de la fibrinólisis, lo que indica un estado hipercoagulable en pacientes con COVID-19 $(45,46)$. Además, la hipoxia grave encontrada en COVID-19 puede estimular la trombosis no solo al aumentar la viscosidad sanguínea, sino vía señalización dependiente del factor de transcripción inducible por hipoxia. Como evidencia se ha informado la oclusión y la formación de microtrombosis en pequeños vasos pulmonares de pacientes críticos con COVID-19 (47). Con base en el argumento anterior, se ha sugerido la aplicación temprana de la terapia anticoagulante en COVID-19 grave, para mejorar el resultado en el grupo de pacientes críticamente enfermos; sin embargo, hasta ahora no se han señalado criterios específicos de inclusión o exclusión (48).

La heparina de bajo peso molecular (HBPM) ha sido el anticoagulante más utilizado para prevenir la CID y el tromboembolismo venoso (TEV) (49). Otros 
anticoagulantes, como la trombomodulina soluble recombinante o la antitrombina, aún no están disponibles en países fuera de Japón. Debido a la evidencia, se sugiere que la prevalencia y los factores de riesgo genético de TEV varían significativamente entre las poblaciones étnicas, y la incidencia de TEV en las poblaciones asiáticas (21-29 casos por 100000 individuos por año) es más baja (50). Una dosis más alta de HBPM podría considerarse en pacientes no asiáticos con COVID-19 grave. Sin embargo, la efectividad de la terapia anticoagulante para la CID asociada con sepsis sigue siendo controvertida (51).

Aunque la directriz japonesa para el tratamiento de la sepsis se pronuncia contra el uso de la heparina o los análogos de heparina como tratamiento estándar en CID asociada con sepsis, algunos estudios sugieren que los pacientes sépticos podrían beneficiarse del reconocimiento temprano y el tratamiento específico con esta terapia (52). Como la disminución del recuento de plaquetas y la prolongación del TP se correlacionan con un aumento de la mortalidad, y la hipofibrinogenemia no es común en la sepsis, el International Society on Thrombosis and Haemostasis (ISTH) desarrolló los criterios de la coagulopatía inducida por sepsis (SIC) para guiar la terapia anticoagulante; la utilidad de esta puntuación simple se ha validado previamente (53).

Un solo artículo evaluó el uso de anticoagulantes en COVID-19 grave (54). Este trabajo, realizado en China, propuso una nueva categoría, que identifica una fase anterior de CID asociada con sepsis, llamada coagulopatía inducida por sepsis; los pacientes que cumplen con los criterios de diagnóstico de SIC podrían beneficiarse de la terapia anticoagulante (52). Los resultados finales del estudio sugieren que solo los pacientes que cumplen con los criterios de SIC, o con dímero D notablemente elevado, pueden beneficiarse de la terapia anticoagulante, principalmente con HBPM.

En un reporte retrospectivo de 7 pacientes con COVID-19 e isquemia distal, en Wuhan, los pacientes te- nían cianosis en los dedos de los pies, gangrena seca y lesiones bulbosas en piel, con dímero D, fibrinógeno y productos de degradación de fibrinógeno elevados (55). Las heparinas de bajo peso molecular mejoraron los exámenes de laboratorio, pero no los síntomas, y 5 pacientes fallecieron. Se considera que se debe monitorizar la posibilidad de un estado hipercoagulable y anticoagulación en casos seleccionados.

Por otro lado, está demostrado el alto riesgo de enfermedad tromboembólica de todo paciente crítico. Los pacientes con COVID-19 crítico desarrollan una respuesta inflamatoria severa asociada con tormenta de citocinas, SDRA e hipoxemia severa, con alteraciones de la coagulación, dada por aumento de dímero $\mathrm{D}$ y fibrinógeno $y$, en raros casos, con coagulopatía de consumo $(46,47)$. También, en varios estudios se han demostrado episodios trombóticos venosos en pacientes con COVID-19. Este riesgo parece ser alto en pacientes graves o críticos que requieren ingreso a UCI y cursan con obesidad; estos pueden tener complicaciones trombóticas en catéteres, filtros de diálisis, oxigenadores ECMO y eventos trombóticos arteriales, como isquemia de extremidades y enfermedad cerebrovascular. Adicionalmente, el tromboembolismo pulmonar se ha identificado recientemente como el evento trombótico más común, a pesar de la tromboprofilaxis (56-60).

En razón a lo anterior se propone la evaluación del riesgo de eventos trombóticos y, en razón a esto, el inicio de la terapia anticoagulante (Tabla 5) (61).

\section{Recomendaciones anticoagulantes}

- No utilizar terapia anticoagulante de rutina en pacientes con COVID-19 grave.

- Realizar anticoagulación profiláctica en pacientes con COVID-19 grave.

- En pacientes con alto riesgo de trombosis se sugiere usar anticoagulación, con monitorización estrecha del riesgo y beneficio. 
Tabla 5. Indicaciones de anticoagulación en COVID-19

\begin{tabular}{|c|c|c|c|}
\hline \multicolumn{4}{|c|}{$\begin{array}{c}\text { Niveles de riesgo trombótico en pacientes con COVID-19 con requerimiento de } \mathrm{O}_{2} \\
\text { o ventilación mecánica ajustada a IMC }\end{array}$} \\
\hline Riesgo bajo & Riesgo intermedio & Riesgo alto & Riesgo muy alto \\
\hline $\begin{array}{l}\text { Pacientes no } \\
\text { hospitalizados, } \\
\text { con IMC <30 kg/ } \\
\mathrm{m}^{2} \text { y sin factores } \\
\text { de riesgo para } \\
\text { tromboembolismo } \\
\text { (cáncer, historia } \\
\text { reciente de } \\
\text { trombosis) }\end{array}$ & $\begin{array}{l}\text { IMC }<30 \mathrm{~kg} / \mathrm{m}^{2}, \text { sin } \\
\text { necesidad de terapia } \\
\text { con oxígeno por } \\
\text { cánula nasal de alto } \\
\text { flujo o ventilación } \\
\text { mecánica, con o sin } \\
\text { factores de riesgo para } \\
\text { tromboembolismo }\end{array}$ & $\begin{array}{l}\text { - IMC }<30 \mathrm{~kg} / \mathrm{m}^{2}, \text { con necesidad de } \\
\text { terapia con oxígeno por cánula } \\
\text { nasal de alto flujo o ventilación } \\
\text { mecánica, con o sin factores de } \\
\text { riesgo para tromboembolismo } \\
\text { - IMC }>30 \mathrm{~kg} / \mathrm{m}^{2} \text {, sin necesidad de } \\
\text { terapia con oxígeno por cánula } \\
\text { nasal de alto flujo o ventilación } \\
\text { mecánica, pero con factores de } \\
\text { riesgo para tromboembolismo } \\
\text { - IMC }>30 \mathrm{~kg} / \mathrm{m}^{2}, \text { con necesidad de } \\
\text { terapia con oxígeno por cánula } \\
\text { nasal de alto flujo o ventilación } \\
\text { mecánica, y sin factores de } \\
\text { riesgo para tromboembolismo }\end{array}$ & $\begin{array}{l}\text { IMC }>30 \mathrm{~kg} / \mathrm{m}^{2} \text {, con necesidad } \\
\text { de terapia con oxígeno por } \\
\text { cánula nasal de alto flujo } \\
\text { o ventilación mecánica, y } \\
\text { con factores de riesgo para } \\
\text { tromboembolismo } \\
\text { - ECMO (venovenoso o } \\
\text { venoarterial) } \\
\text { - Trombosis de catéter } \\
\text { - Trombosis del filtro de diálisis } \\
\text { - Síndrome inflamatorio marcado o } \\
\text { hipercoagulabilidad (fibrinógeno } \\
>8 \mathrm{~g} / \mathrm{L}(800 \mathrm{mg} / \mathrm{dL} \text { ) o dímero D } \\
>3 \mu \mathrm{g} / \mathrm{mL} \text { o } 3000 \mathrm{ng} / \mathrm{mL} \text { ) }\end{array}$ \\
\hline Tratamiento & Tratamiento & Tratamiento & Tratamiento \\
\hline $\begin{array}{l}\text { - Enoxaparina } 40 \\
\text { mg/día SC } \\
\text { - Enoxaparina } 20 \\
\text { mg/día SC, si TFG } \\
\text { 15-30 mL/min } \\
\text { - Heparina NF } 5000 \\
\text { UI SC cada } 12 \\
\text { horas, si TFG <15 } \\
\text { mL/min }\end{array}$ & $\begin{array}{l}\text { - Enoxaparina } 40 \text { mg/ } \\
\text { día SC } \\
\text { - Enoxaparina } 20 \mathrm{mg} / \\
\text { día SC, si TFG } 15-30 \\
\text { mL/min } \\
\text { - Heparina NF } 5000 \mathrm{UI} \\
\text { SC cada } 12 \text { horas, si } \\
\text { TFG <15 mL/min }\end{array}$ & 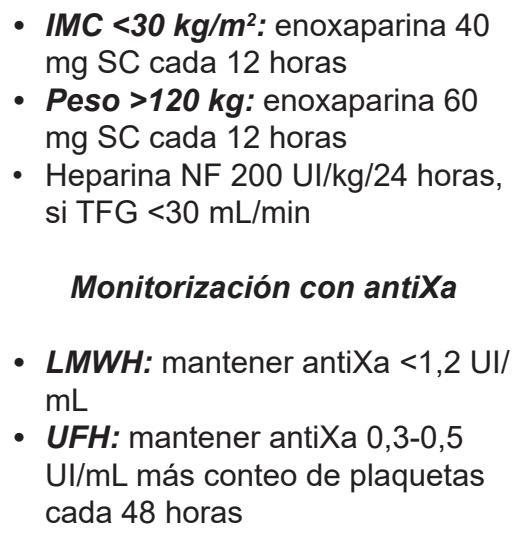 & $\begin{array}{l}\text { - Enoxaparina } 1 \mathrm{mg} / \mathrm{kg} \mathrm{SC} \text { cada } \\
12 \text { horas, no exceder } 100 \mathrm{mg} \\
\text { cada } 12 \text { horas } \\
\text { - Heparina NF } 500 \mathrm{UI} / \mathrm{kg} / 24 \\
\text { horas, sí TFG <30 mL/min } \\
\text { Monitorización con antiXa } \\
\text { - } \mathbf{L} \text { MWH: mantener antiXa }<1,2 \\
\text { UI/mL } \\
\text { - UFH: mantener antiXa 0,5-0,7 } \\
\text { Ul/mL más conteo de plaquetas } \\
\text { cada } 48 \text { horas }\end{array}$ \\
\hline
\end{tabular}

ECMO: membrana de oxigenación extracorpórea; IMC: índice de masa corporal; SC: subcutáneo; TSG: tasa de filtración glomerular.

\section{Corticoides en manejo de pacientes con neumonía por SARS-CoV-2}

Los pacientes que cursan con neumonía grave por SARS-CoV-2 tienen alta probabilidad de progresión rápida e insuficiencia respiratoria aguda, asociada con una respuesta inflamatoria exagerada, la cual puede derivar en SDRA o disfunción orgánica múltiple $(62,63)$.

La hiperinflamación en SARS-CoV-2 podría ser un factor de gravedad, susceptible de interven- ciones terapéuticas específicas (64). En estudios retrospectivos se ha buscado demostrar que la inflamación sistémica se asocia con desenlaces adversos, y cómo su intervención con esteroides puede mitigar el daño de órganos.

En pacientes con COVID-19 grave se han demostrado niveles séricos significativamente más altos de TNF- $\alpha$, IL-1 e IL- 6 frente a los pacientes no graves (65). Además, en los casos graves se identificó una reducción de las poblaciones de linfocitos T CD4+ y CD8+, y una disminución de las células T reguladoras, 
probablemente debido a la alta expresión de citocinas proinflamatorias en este grupo de pacientes.

La gravedad del COVID-19 está asociada con un síndrome de tormenta de citocinas, semejante a linfohistiocitosis hemofagocítica secundaria (LHs) (66). Así como se observa en LHs, los factores ambientales pueden desencadenar o exacerbar una respuesta inmune innata y adquirida aberrante, con síntesis masiva de citocinas en sujetos genéticamente susceptibles (67). Por ello proponen que todos los pacientes con COVID-19 grave se deberían evaluar, para definir o descartar una posible hiperinflamación, con laboratorios, como ferritina, trombocitopenia y eritrosedimentación, y plantean que realizar el HScore permitiría identificar el subgrupo de pacientes, en quienes la terapia inmunosupresora podría mejorar la mortalidad (68).

Durante el brote de SAR, en los años 2002 y 2003, los pacientes con SARS probable (diagnosticados según los criterios de OMS) se trataron de acuerdo con un protocolo con antibacterianos, asociado con una combinación de ribavirina y metilprednisolona. La mayoría de los pacientes que recibieron metilprednisolona en dosis por pulsos y dosis por horario tuvieron bajo requerimiento de soporte ventilatorio y menor progresión a estado grave (69).

La revisión sistemática publicada en PLOS Medicine, que incluyen los estudios observacionales con el uso de corticosteroides en pacientes con SARS, no reportó beneficios de supervivencia y posibles daños asociados (necrosis avascular, psicosis, diabetes y aclaramiento viral tardío) (70).

La presentación clínica de neumonía por SARSCoV-2 es indistinguible del compromiso infeccioso y neumonía por influenza (71). Revisiones sistemáticas recientemente publicadas, que evalúan el uso de corticoides en neumonía por influenza, son consistentes en documentar que la terapia con corticosteroides se asoció con un aumento de la mortalidad (OR 3,90; IC $95 \%$ 2,31-6,60) $(72,73)$.

En los pacientes con neumonía grave por COVID-19 del hospital de Wuhan, en enero de 2020, que recibieron metilprednisolona en dosis de $1-2 \mathrm{mg} / \mathrm{kg} /$ día durante 5-7 días IV frente a los que no recibieron cor- ticoides, se observó que el número de días necesarios para alcanzar la temperatura corporal en rango normal fue significativamente más corto $(2,06 \pm 0,28$ frente a $5,29 \pm 0,70 ; P=0,010)$, y tuvieron una mejoría más rápida de $\mathrm{SaO}_{2}$ y uso de oxígeno por menos días $(8,2$ días [IQR 7,0-10,3] frente a 13,5 días (IQR 10,3-16); $P<0,001)$ (74).

En otro estudio retrospectivo observacional en China, 10 pacientes con COVID-19 recibieron corticosteroides con dosis a corto plazo (160 mg/día) asociado con inmunoglobulina ( $20 \mathrm{~g} /$ día). Como respuesta al tratamiento combinado, el recuento de linfocitos $(0,88 \pm$ $0,34$ frente a $0,59 \pm 0,18 ; P<0,05)$ e índice de oxigenación $\mathrm{SPO}_{2}(94,90 \pm 2,51$ frente a 90,50 $\pm 5,91, P<0,05)$ y $\mathrm{PaO}_{2} / \mathrm{FiO}_{2}(321,36 \pm 136,91$ frente a 129,30 $\pm 64,97 ; P$ $<0,05)$ presentaron una mejoría significativa (75).

Los estudios realizados durante las etapas tempranas de la pandemia por SARS-CoV-2 en 2020 tienen como principal limitación el bajo número de pacientes, así como desenlaces de bajo impacto, lo cual es insuficiente, por el momento, para lograr soportar una recomendación en favor del uso de corticoides en este escenario.

En junio de 2020 se publicaron los resultados preliminares de uno de los brazos del ensayo clínico del estudio RECOVERY, en el cual se compararon 2104 pacientes asignados al azar para recibir dexametasona frente a 4321 pacientes asignados simultáneamente al tratamiento habitual (76). Los pacientes se asignaron en una proporción de 2:1 al tratamiento estándar o habitual o al tratamiento habitual más $6 \mathrm{mg}$ de dexametasona 1 vez al día (oral o intravenosa) durante un máximo de 10 días (o hasta el alta, si era antes). 454 $(21,6 \%)$ pacientes asignados a la intervención con dexametasona y 1065 (24,6\%) pacientes asignados al tratamiento habitual fallecieron a los 28 días (índice de frecuencia ajustada por edad [RR] 0,83; IC 95\% 0,74$0,92 ; P<0,001)$.

Las reducciones de la tasa de mortalidad proporcional y absoluta variaron significativamente, dependiendo del nivel de soporte respiratorio en el momento de la aleatorización $(p<0,001)$. El uso de dexametasona redujo la mortalidad a los 28 días en $35 \%$, en pacientes que recibieron ventilación mecánica invasiva (RR $0,65$; IC $95 \% 0,51-0,82]$; $p<0,001$ ) y en $20 \%$ en pa- 
cientes que recibieron oxígeno sin ventilación mecánica invasiva (RR 0,80; IC 95\% 0,70-0,92; $p=0,002$ ); sin embargo, no hubo evidencia de beneficio entre aquellos pacientes que no estaban recibiendo soporte respiratorio (RR 1,22; IC 95\% 0,93-1,61]; $p=0,14$ ). La evaluación de grupos específicos define un beneficio de la intervención con dexametasona con pacientes menores de 70 años (RR 0,64; IC 95\% 0,52-0,78) más de 7 días de síntomas (RR 0,68; IC 95\% 0,58-0,80).

\section{Recomendaciones para esteroides}

- Ante los resultados del estudio RECOVERY se considera el beneficio del uso de dexametasona en pacientes con requerimiento de ventilación mecánica o que requieran oxígeno con más de 7 días de sintomatología. No debe utilizarse en escenarios diferentes a los descritos.

- El uso de corticoides con otras indicaciones diferentes de COVID-19 no deben tener ninguna restricción.

- Dada la falta de información derivada de estudios clínicos que documenten la efectividad y el posible daño, los corticoides de rutina deben evitarse, a menos que se indiquen por una razón específica.

\section{Plasma convaleciente (PC)}

Dada la falta de evidencia para el tratamiento de la infección por SARS-CoV-2 y las vacunas, las intervenciones clásicas e históricas han resurgido como opciones para el control de la enfermedad. Ese es el caso del PC, una estrategia de inmunización pasiva que se ha utilizado en la prevención y el tratamiento de pacientes con enfermedades infecciosas, para mejorar la tasa de supervivencia desde principios del siglo XX (77). El PC se obtiene mediante aféresis en sobrevivientes con infecciones previas causadas por patógenos de interés, en los que se desarrollan anticuerpos contra el agente causal de la enfermedad. El objetivo principal es neutralizar el patógeno para su erradicación y, dada su rápida obtención, el PC se ha considerado como una intervención de emergencia.

Durante la aféresis, además de los anticuerpos neutralizantes $(\mathrm{AcN})$, de los donantes se obtienen otras proteínas, como las citocinas antiinflamatorias, los fac- tores de coagulación, los anticuerpos naturales, las defensinas, las pentraxinas y otras proteínas, con posibles funciones inmunomoduladores (78). La transfusión de PC a pacientes infectados, además del control de la carga viral, puede proporcionar beneficios adicionales, como la inmunomodulación, a través de la mejoría de la respuesta inflamatoria severa. Este último podría ser el caso de la infección por COVID-19, en el que una sobreactivación del sistema inmune puede generar una hiperinflamación sistémica o "tormenta de citocinas", propiciada por IL-1 $\beta$, IL-2, IL-6, IL-17, IL-8, TNF $\alpha$ y CCL2 $(79,80)$. Esta reacción inflamatoria puede perpetuar el daño pulmonar, que implica fibrosis y la reducción de la capacidad pulmonar. Hasta el momento se han registraron más de 56 ensayos clínicos en los que se evaluará el papel del PC en COVID-19.

Actualmente, el PC utilizado en pacientes con COVID-19 demostró reducir la carga viral y mejorar el estado clínico (81-83). Si bien los resultados de algunos de los ensayos clínicos más recientes son alentadores, la validación de estos resultados en grandes ensayos clínicos asignados al azar y controlados con placebo es necesaria para establecer aún más la efectividad de la terapia con PC. La dosis y frecuencia de PC son dos de los criterios que pueden requerir una mayor optimización para mejorar aún más la eficacia de la terapia para COVID-19.

Recientemente se compilaron dos series de casos en China, que examinan el uso terapéutico de la PC en pacientes con COVID-19 (81, 82). Entre los dos estudios se trató a un total de 15 pacientes, todos estaban gravemente enfermos antes de la transfusión, y fueron positivos para SARS-CoV-2 por PCR. Se evaluó el título de anticuerpos neutralizantes de plasma del donante ( $\geq 40$ en el estudio de 5 pacientes; $\geq 640$ en el estudio de 10 pacientes). Todo el plasma se trató con fotoquímica de azul de metileno y se almacenó a $4{ }^{\circ} \mathrm{C}$ (nunca congelado). Ambos estudios mostraron una mejora en muchos aspectos, incluida la eliminación del virus, la disminución de la necesidad de oxígeno suplementario y de la ventilación mecánica, la normalización de los valores de laboratorio y la mejora de los hallazgos pulmonares radiológicos.

No existe una dosis estándar de transfusión de PC. En diferentes estudios para coronavirus, la administración de PC oscila entre 200 y 500 mL, en dosis de es- 
quema único o doble. Actualmente, la recomendación es administrar $3 \mathrm{~mL} / \mathrm{kg}$ por dosis en 2 días. Esta estrategia facilita la distribución de unidades de plasma (250 $\mathrm{mL}$ por unidad) y proporciona una opción estándar de entrega en estrategias de salud pública (84).

\section{Recomendación PC}

Uso solo bajo estudios de investigación clínica.

\section{Vacunación}

Indiscutiblemente, la mejor estrategia a largo plazo para frenar la escala del impacto humanitario y económico de la pandemia de COVID-19 es desarrollar una vacuna eficaz, que pueda prevenir las nuevas infecciones y detener la transmisión de la enfermedad. La comunidad científica y la industria de las vacunas han respondido con urgencia a esta epidemia de SARS-CoV-2 para apoyar el desarrollo de vacunas contra COVID-19.

La demanda de la situación y la disponibilidad de múltiples plataformas tecnológicas de vacunas también ha acelerado el desarrollo de muchas vacunas candidatas para el COVID-19, con una rapidez sin precedentes, y algunos de estos candidatos ya han ingresado a pruebas clínicas en humanos. La cartera de vacunas contra el COVID-19 ya ha alcanzado más de 100 vacunas candidatas activas confirmadas, aunque la mayoría, al momento, se encuentra en etapas exploratorias o preclínicas (Tabla 6) (85).

Algunos estudios también sugieren que las vacunas para otras enfermedades pueden conferir resistencia al SARS-CoV-2. Dos informes recientes sugirieron una correlación entre los países vacunados con Bacille Calmette-Guérin (BCG; antituberculosis) y la reducción de la mortalidad en pacientes con COVID-19. Se sabe que el BCG proporciona efectos protectores inespecíficos, al aumentar la inmunidad innata para tratar tumores malignos, como el cáncer de vejiga, el melanoma, el linfoma y la leucemia. Específicamente, el BCG puede aumentar la primera línea de defensa inmune (llamada inmunidad entrenada) para proporcionar una mejor defensa contra las infecciones bacterianas, parasitarias y virales $(85)$.

Tabla 6. Lista de plataformas y objetivos de producción de vacunas para el SARS-CoV-2

\begin{tabular}{|c|c|c|}
\hline Empresas/Universidades & Objetivo para la vacuna & Cronología estimada \\
\hline Inovio Pharmaceuticals, EE. UU. & Vacuna basada en ADN & $\begin{array}{l}\text { Se espera que comience en los próximos } \\
\text { meses para pruebas en humanos }\end{array}$ \\
\hline CureVac, Alemania & Vacunas basadas en ARN & $\begin{array}{l}\text { Los ensayos en humanos comenzarían } \\
\text { este verano, y son capaces de generar } 1 \\
\text { millón de dosis }\end{array}$ \\
\hline Novavax & Vacunas a base de nanopartículas & $\begin{array}{l}\text { Se espera que comience en } 3 \text { meses para } \\
\text { pruebas en humanos }\end{array}$ \\
\hline Johnson \& Johnson & $\begin{array}{l}\text { Tecnología vectorizada con adenovirus, } \\
\text { utilizada para candidatos a vacunas } \\
\text { contra el zika, el ébola y el VIH }\end{array}$ & $\begin{array}{l}\text { Se espera que se lance en } 1 \text { año al } \\
\text { mercado }\end{array}$ \\
\hline Universidad de Hong Kong & $\begin{array}{l}\text { Vacuna contra la influenza en aerosol } \\
\text { nasal modificada }\end{array}$ & $\begin{array}{l}\text { Se espera que comience en } 1 \text { año para } \\
\text { ensayos clínicos en humanos }\end{array}$ \\
\hline GeoVax-BravoVax & $\begin{array}{l}\text { Plataforma de vacunas modificadas de } \\
\text { Vaccina-Ankara-Virus-Like Particles } \\
\text { (MVA-VLP) }\end{array}$ & No disponible \\
\hline $\begin{array}{l}\text { Shanghai East Hospital } \\
\text { (Universidad de Tongil)- } \\
\text { Stermirna Therapeutics }\end{array}$ & Vacuna basada en ARNm & $\begin{array}{l}\text { Se espera que comience en } 2 \text { meses para } \\
\text { ensayos clínicos }\end{array}$ \\
\hline
\end{tabular}




\section{Manejo clínico de un caso sospechoso o confirmado de SARS-CoV-2 (COVID-19)}

La decisión de ingreso o de manejo se tomará desde el servicio de Urgencias en Triaje y valoración médica inicial en Urgencias.

\section{Triaje}

- Preguntas relacionadas con síntomas respiratorios.

- Criterios clínicos y epidemiológicos para determinar si cumple las definiciones operativas de caso.

- Si se cumplen los criterios se debe direccionar al sitio de atención institucional para COVID-19.

\section{Aproximación de manejo por médicos de Urgencias}

Para definir la severidad del cuadro clínico se aplicarán, en primera instancia, los criterios CURB-65 o CRB-65, cuyos parámetros se muestran en la Figura 6.

\section{Recomendaciones finales}

Como recomendación final, es indispensable que en este momento de pandemia por SARS-CoV-2, nuestra comunidad se adhiera a las recomendaciones de higiene de manos, higiene de la tos, aislamiento físico y social, y uso de mascarilla quirúrgica en todo momento, cuando no se pueda cumplir con el aislamiento físico o social. Todas nuestras instituciones deben optimizar y cumplir con la normatividad para atender a los pacientes con infecciones respiratorias agudas, y determinar áreas específicas de atención para COVID-19, con rutas de ingreso, traslado, hospitalización y egreso, y que se apliquen las normas de precauciones estándar y especiales en pacientes hospitalizados.

Esta concientización de la población general, del área administrativa y del personal asistencial de nuestras instituciones de salud, nos permitirá afrontar las epidemias y endemias a las cuales nos estamos enfrentando cada día con mayor frecuencia. Si somos conscientes de esta situación, realmente podremos salvar vidas con medidas que solo requieren compromiso ciudadano.

En el manejo del COVID-19, la plausibilidad biológica es una justificación insuficiente para usar tratamientos, especialmente porque nuestra historia está llena de medicamentos con lógicos mecanismos y resultados in vitro que terminaron haciendo daño. Diversos autores aceptan que, en casos seleccionados, se empleen terapias no demostradas; pero, el uso rutinario de medicamentos para COVID-19, fuera de estudios clínicos, reta la credibilidad, especialmente porque muchos de ellos pueden producido daño.

El estrés, la fatiga o el deseo innato de ayudar al paciente pueden ser razones para que los médicos abandonen el cuidado estándar para usar medicamentos sin evidencia científica. Este enfoque sin datos, soportado en el vano intento de hacer algo, lo que sea, con la supuesta idea de beneficiar y dar esperanzas, puede generar un gravísimo escenario, en el cual, si el paciente mejora fue por el medicamento, y si se muere fue por la gravedad de la enfermedad. Contrario a esto, los autores proponen que la estrategia demostrada para superar sesgos es el método científico y la aplicación de estudios clínicos, para determinar si un medicamento es efectivo o dañino. Por el bien de nuestros pacientes necesitamos saber qué funciona y qué no; así, la hipótesis nula debería ser: los pacientes con COVID-19 mejoran con la atención basada en un protocolo establecido, y debe ser rechazada o aceptada en estudios controlados; actuar de manera diferente es irracional, arrogante e imprudente (86).

A la espera de estudios clínicos en curso, debemos resistir el deseo innato de actuar sobre la emoción y confiar en nuestro credo: primero, no hacer daño. Dado la voluminosa experiencia en la pandemia, el presente documento será actualizado en la medida que aparezca evidencia suficiente. 


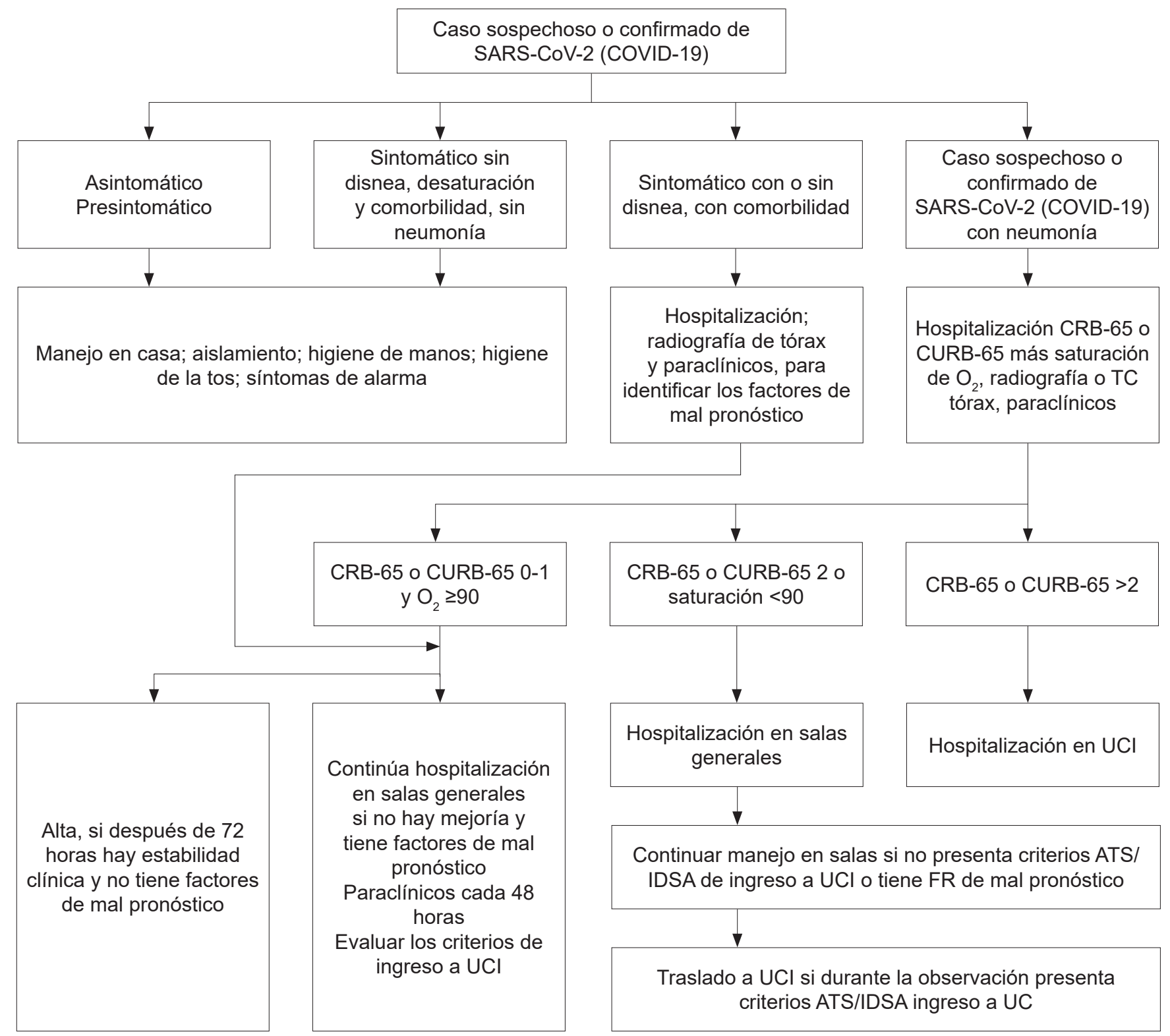

Figura 6. Flujograma de hospitalización que combina criterios CRB-65 o CURB-65, oximetría y criterios ATS/IDSA.

\section{Referencias}

1. World Health Organization [Internet]. Novel coronavirus (2019-nCoV). Disponible en: https://apps.who.int/iris/handle/ $10665 / 330775$

2. World Health Organization [Internet]. Coronavirus disease (COVID-19) technical guidance: Laboratory testing for 2019nCoV in humans. Disponible en: https://www.who.int/emergencies/diseases/novel-coronavirus-2019/technical-guidance/ laboratory-guidance/

3. Organización Panamericana de la Salud[Internet]. Actualización epidemiológica nuevo coronavirus (2019-nCoV). Última visita: 20 de enero de 2020. Disponible en: https://www.paho.org/hq/ index.php?option=com_docman\&view=download\&category slug $=$ coronavirus-alertas-epidemiologicas \&alias $=51355$ 20-de-enero-de-2020-nuevo-coronavirus-ncov-actualizacionepidemiologica-1\&Itemid=270\&lang=en

4. World Health Organization [Internet]. Infecciones por coronavirus. Disponible en: https://www.who.int/csr/disease/coronavirus_infections/es/

5. World Health Organization [Internet]. Global surveillance for human infection with coronavirus disease (COVID-19). Última visita: Disponible en: https://www.who.int/publicationsdetail/global-surveillance-for-human-infection-with-novelcoronavirus-(2019-ncov) 
6. World Health Organization [Internet]. Novel Coronavirus (2019-nCoV) situation report. Disponible en: https://apps. who.int/iris/bitstream/handle/10665/330778/nCoVsitrep02Feb2020-eng.pdf

7. John Hopkins University. COVID-19 dashboard by the Center for Systems Science and Engineering (CSSE). Disponible en: https://gisanddata.maps.arcgis.com/apps/opsdashboard/index. html\#/bda7594740fd40299423467b48e9ecf6

8. Munster VJ, Koopmans M, van Doremalen N, van Riel D, de Wit M. A novel coronavirus emerging in China - Key questions for impact assessment. N Engl J Med. 2020;382(8):6924. doi: 10.1056/NEJMp2000929.

9. Zhu N, Zhang D, Wang W, Li X, Yang B, Song I, et al. A novel coronavirus from patients with pneumonia in China, 2019. N Engl J Med. 2020;382:727-33. doi: 10.1056/NEJMoa2001017.

10. Li Q, Guan X, Wu P, Wang X, Zhou L, Tong Y, et al. Early transmission dynamics in Wuhan, china, of novel coronavirus-infected pneumonia. N Engl J Med. 2020;382(13):1199207. doi: 10.1056/NEJMoa2001316.

11. Paules C, Marston H, Fauci A. Coronavirus infections - More than just the common cold. JAMA. 2020;323(8):707-8. doi:10.1001/jama.2020.0757.

12. Ministerio de Salud [Internet]. Nuevo coronavirus (nCoV). Disponible en: https:/www.minsalud.gov.co/salud/publica/ PET/Paginas/Nuevo-Coronavirus-nCoV.aspx

13. Ministerio de Salud [Internet]. Manual de medidas básicas para el control de infecciones en IPS. Disponible en: https:// www.minsalud.gov.co/salud/publica/PET/Paginas/Covid-19 copia.aspx.

14. Organización Panamericana de la Salud [Internet]. Prevención y control de infecciones asociadas a la atención de la salud recomendaciones básicas. Disponible en: https://www.paho.org/hq/ index.php?option=com_docman\&view=download\&category_ slug=guias-5603\&alias=47902-recomendaciones-basicas-para-la-prevencion-y-control-de-infecciones-asociadas-a-la-atencion-de-la-salud-1\&Itemid=270\&lang=es

15. Patel A, Jernigan DB; 2019-nCoV CDC Response Team. Initial public health response and interim clinical guidance for the 2019 novel coronavirus outbreak - United States, December 31, 2019-February 4, 2020. MMWR Morb Mortal Wkly Rep. 2020;69(5):140-6. doi: 10.15585/mmwr.mm6905e1.

16. Chen N, Zhou M, Dong X, Qu J, Gong F, Han Y, et al. Epidemiological and clinical characteristics of 99 cases of 2019 novel coronavirus pneumonia in Wuhan, China: a descriptive study. Lancet. 2020;395(10223):507-13. doi: 10.1016/S01406736(20)30211-7.

17. Lu R, Zhao X, Li J, Niu P, Yang B, Wu H, et al. Genomic characterization and epidemiology of 2019 novel coronavirus: implications for virus origins and receptor binding. Lancet. 2020;395(10224):565-74. doi: 10.1016/S01406736(20)30251-8.
18. Huang C, Wang Y, Li X, Zhao J, Hun Y, Zhang L, et al. Clinical features of patients infected with 2019 novel coronavirus in Wuhan, China. Lancet. 2020;395(10223):497-506. doi: 10.1016/S0140-6736(20)30183-5.

19. Guan WJ, Ni ZY, Hu Y, Liang WH, Ou CQ, He JX, et al. Clinical characteristics of coronavirus disease 2019 in China. N Engl J Med. 2020;382:1708-20. doi: 10.1056/NEJMoa2002032.

20. Feng Y, Ling Y, Bai T, Xie Y, Huang J, Li J, et al. COVID-19 with different severity: a multi-center study of clinical features. Am J Respir Crit Care Med. 2020;201(11):1380-8. doi: 10.1164/rccm.202002-0445OC.

21. Ji D, Zhang D, Xu J, Chen Z, Yang T, Zhao P, et al. Prediction for progression risk in patients with COVID-19 pneumonia: the CALL score. Clin Infect Dis. 2020;71(6). doi: https://doi. org/10.1093/cid/ciaa414.

22. Zhou F, Yu T, Du R, Fan G, Liu Y, Liu Z, et al. Clinical course and risk factors for mortality of adult inpatients with COVID-19 in Wuhan, China: a retrospective cohort study. Lancet. 2020;395:1054-62. doi: 10.1016/S0140-6736(20)30566-3.

23. Guo L, Wei D, Zhang X, Wu Y, Li Q, Zhou M, et al. Clinical features predicting mortality risk in patients with viral pneumonia: The MuLBSTAScore. Front Microbiol. 2019;10:2752. doi: 10.3389/fmicb.2019.02752.

24. Yang X, Yu Y, Xu J, Shu H, Xia J, Liu H, et al. Clinical course and outcomes of critically ill patients with SARS-CoV-2 pneumonia in Wuhan, China: a single-centered, retrospective, observational study. Lancet Respir Med. 2020;8(5):475-81. doi: 10.1016/S2213-2600(20)30079-5.

25. Ruan Q, Yang K, Wang W, Jiang L, Song J. Clinical predictors of mortality due to COVID-19 based on an analysis of data of 150 patients from Wuhan, China. Intensive Care Med. 2020;46(5):846-8. doi: 10.1007/s00134-020-05991-x.

26. Bai L, Yang D, Wang X, Tong L, Zhu X, Zhong N, et al. Chinese experts' consensus on the Internet of things-aided diagnosis and treatment of coronavirus disease 2019 (COVID-19). Clinical eHealth. 2020;3:7-15. doi: https://doi.org/10.1016/j. ceh.2020.03.001.

27. Rubin GD, Ryerson CJ, Haramati LB, Sverzellati N, Kanne JP, Raoof S, et al. The role of chest imaging in patient management during the COVID-19 pandemic: a multinational consensus statement from the Fleischner Society. Chest. 2020;296(1). doi: https://doi.org/10.1016/j.chest.2020.04.003.

28. Simpson S, Kay F, Abbara S, Bhalla S, Chung JH, Chung M, et al. Radiological Society of North America expert Consensus Statement on Reporting Chest CT findings related to COVID-19: endorsed by the Society of Thoracic Radiology, the American Colleges of Radiology, and RSNA. Radiol Cardiothor Imag. 2020;2(2):e200152. doi: https://doi. org/10.1148/ryct.2020200152.

29. British Society of Thoracic Imaging. COVID-19 BSTI imaging database. Disponible en: https://www.bsti.org.uk/training-andeducation/covid-19-bsti-imaging-database/ 
30. Cheng Z, Lu Y, Cao Q, Qin L, Pan Z, Yan F, et al. Clinical features and chest CT manifestations of coronavirus disease 2019 (COVID-19) in a single-center study in Shanghai, China. Am J Roentgenol. 2020;215:121-6. 10.2214/AJR.20.22959.

31. Salehi S, Abedi A, Balakrishnan S, Gholamrezanezhad A. Coronavirus disease 2019 (COVID-19): a systematic review of imaging findings in 919 patients. Am J Roentgenol. 2020;215:87-93. 10.2214/AJR.20.23034.

32. Ai T, Yang Z, Hou H, Zhan C, Chen C, Lv W, et al. Correlation of chest CT and RTPCR testing in coronavirus disease 2019 (COVID-19) in China: a report of 1014 cases. Radiology. 2020:200642. doi: 10.1148/radiol.2020200642.

33. Ye Z, Zang Y, Wang Y, Song B. Chest CT manifestations of new coronavirus disease 2019 (COVID-19): a pictorial review. Eur Radiol. 2020;30:4381-9. doi: https://doi.org/10.1007/ s00330-020-06801-0.

34. Infectious Diseases Society of America [Internet]. Infectious Diseases Society of America Guidelines on the treatment and management of patients with COVID-19. Disponible en: https://www.idsociety.org/practice-guideline/covid-19-guideline-treatment-and-management/

35. Jin YH, Cai L, Cheng ZH, Cheng H, Deng T, Fan YP, et al. A rapid advice guideline for the diagnosis and treatment of 2019 novel coronavirus (2019-nCoV) infected pneumonia (standard version). Mil Med Res. 2020;7:4. doi: 10.1186/ s40779-020-0233-6.

36. University of Oxford [Internet]. Statement from the Chief Investigators of the randomised evaluation of COVID-19 therapy (RECOVERY) trial on lopinavir-ritonavir. 2020. Disponible en: https://www.recoverytrial.net/files/lopinavirritonavir-recovery-statement-29062020_final.pdf

37. Gautret P, Lagier JC, Parola P, Hoang VT, Meddeb L, Mailhe $\mathrm{M}$, et al. Hydroxychloroquine and azithromycin as a treatment of COVID-19: results of an open-label non-randomized clinical trial. Int J Antimicrob Agents. 2020:105949. doi: 10.1016/j.ijantimicag.2020.105949.

38. Cortegiani A, Ingoglia g, Ippolito M, Giarratano A, Einav S. A systematic review on the efficacy and safety of chloroquine for the treatment of COVID-19. J Crit Care. 2020;57:279-83. doi: https://doi.org/10.1016/j.jcrc.2020.03.005.

39. Silva MG, Fonseca F, Souza V, Almeida M, Cardoso G, Brito M, et al. Effect of high vs. low doses of chloroquine diphosphate as adjunctive therapy for patients hospitalized with severe acute respiratory syndrome coronavirus 2 (SARSCoV-2) infection. JAMA Netw Open. 2020;3(4):e208857. doi: 10.1001/jamanetworkopen.2020.8857.

40. Horby P, Mafham M, Linsell L, Bell JL, Staplin N, Emberson JR, Wiselka M, et al. Effect of hydroxychloroquine in hospitalized patients with COVID-19: preliminary results from a multi-centre, randomized, controlled trial. medRxiv. 2020. doi: https://doi.org/10.1101/2020.07.15.20151852.

41. Beigel JH, Tomashek JM, Dodd LE, Mehta AK, Zingman BS, Kalil AC, et al. Remdesivir for the treatment of COVID-19. N Engl J Med. 2020;383(19):1813-26. doi: 10.1056/NEJMoa2007764.
42. Xu X, Han M, Li T, Sun W, Wang D, Fu B, et al. Effective treatment of severe COVID-19 patients with tocilizumab. Proc Natl Acad Sci USA. 2020;117(20):10970-5. doi: 10.1073/pnas.2005615117.

43. Guaraldi G, Meschiari M, Cozzi-Lepri A, Milic J, Tonelli R, Menozzi M, et al. Tocilizumab in patients with severe COVID-19: a retrospective cohort study. Lancet Rheumatol. 2020;2(8):E474-84. doi: https://doi.org/10.1016/S26659913(20)30173-9.

44. Tang N, Li D, Wang X, Sun Z. Abnormal coagulation parameters are associated with poor prognosis in patients with novel coronavirus pneumonia. J Thromb Haemost. 2020;18(4):8447. doi: $10.1111 /$ jth. 14768 .

45. Schmitt FCF, Manolov V, Morgenstern J, Fleming T, Heitmeier $\mathrm{S}$, Uhle F, et al. Acute fibrinolysis shutdown occurs early in septic shock and is associated with increased morbidity and mortality: results of an observational pilot study. Ann Intensive Care. 2019;9(1):19. doi: 10.1186/s13613-019-0499-6.

46. Gupta N, Zhao Y-Y, Evans CE. The stimulation of thrombosis by hypoxia. Thromb Res. 2019;181:77-83. doi: 10.1016/j. thromres.2019.07.013.

47. Luo W, Yu H, Gou J, Li X, Sun Y, Li J, et al. Clinical pathology of critical patient with novel coronavirus pneumonia (COVID-19). Pathol Pathobiol. 2020. doi: 10.1097/ TP.0000000000003412.

48. Tang N, Bai H, Chen X, Gong J, Li D, Sun Z. Anticoagulant treatment is associated with decreased mortality in severe coronavirus disease 2019 patients with coagulopathy. J Thromb Haemost. 2020;18(5):1094-9. doi: 10.1111/jth.14817.

49. Poterucha TJ, Libby P, Goldhaber SZ. More than an anticoagulant: Do heparins have direct anti-inflammatory effects? Thromb Haemost. 2017;117(3):437-44. doi: 10.1160/TH1608-0620.

50. Stein PD, Kayali F, Olson RE, Milford CE. Pulmonary thromboembolism in Asians/Pacific islanders in the United States: analysis of data from the National Hospital Discharge Survey and the United States Bureau of the Census. Am J Med. 2004;116(7):435-42. doi: 10.1016/j.amjmed.2003.11.020.

51. Aikawa N, Shimazaki S, Yamamoto Y, Saito H, Maruyama I, Ohno R, et al. Thrombomodulin alfa in the treatment of infectious patients complicated by disseminated intravascular coagulation: subanalysis from the phase 3 trial. Shock. 2011;35(4):349-54. doi: 10.1097/SHK.0b013e318204c019.

52. Iba T, Gando S, Thachil J. Anticoagulant therapy for sepsisassociated disseminated intravascular coagulation: the view from Japan. J Thromb Haemost. 2014 Jul;12(7):1010-9. doi: 10.1111/jth.12596.

53. Iba T, Nisio MD, Levy JH, Kitamura N, Thachil J. New criteria for sepsis-induced coagulopathy (SIC) following the revised sepsis definition: a retrospective analysis of a nationwide survey. BMJ Open. 2017;7(9):e017046. doi: 10.1136/bmjopen-2017-017046.

54. Zhang Y, Cao W, Xiao M, Li YJ, Yang Y, Zhao J, et al. [Clinical and coagulation characteristics of 7 patients with criti- 
cal COVID-2019 pneumonia and acro-ischemia]. Zhonghua Xue Ye Xue Za Zhi. 2020;41(0):E006. doi: 10.3760/ cma.j.issn.0253-2727.2020.0006.

55. Ejaz A, Ahmed MM, Tasleem A, Rafay Khan Niazi M, Ahsraf MF, Ahmad I, et al. Thromboprophylaxis in Intensive Care Unit patients: a literature review. Cureus. 2018;10(9):e3341. doi: 10.7759 /cureus.3341.

56. Cui S, Chen S, Li X, Liu S, Wang F. Prevalence of venous thromboembolism in patients with severe novel coronavirus pneumonia. J Thromb Haemost. 2020;18(6):1421-4. doi: $10.1111 /$ jth. 14830 .

57. Klok FA, Kruip MJHA, van der Meer NJM, Arbous MS, Gommers DAMPJ, Kant KM, et al. Incidence of thrombotic complications in critically ill ICU patients with COVID-19. Thromb Res. 2020;191:145-7. doi: 10.1016/j. thromres.2020.04.013.

58. Klok FA, Kruip MJHA, van der Meer NJM, Arbous MS, Gommers D, Kant KM, et al. Confirmation of the high cumulative incidence of thrombotic complications in critically ill ICU patients with COVID-19: an updated analysis. Thromb Res. 2020;191:148-50. doi: 10.1016/j.thromres.2020.04.041.

59. Helms J, Tacquard C, Severac F, Leonard-Lorant I, Ohana M, Delabranche X, et al. High risk of thrombosis in patients with severe SARS-CoV-2 infection: a multicenter prospective cohort study. Intensive Care Med. 2020;46(6):1089-98. doi: 10.1007/s00134-020-06062-x.

60. Poissy J, Goutay J, Caplan M, Parmentier E, Duburcq T, Lassalle F, et al. Pulmonary embolism in patients with COVID-19: awareness of an increased prevalence. Circulation. 2020;142(2):184-6. doi: 10.1161/CIRCULATIONAHA. 120.047430 .

61. Susen S, Tacquard CA, Godon A, Mansour A, Garrigue D, Nguyen P, et al. Prevention of thrombotic risk in hospitalized patients with COVID-19 and hemostasis monitoring. Crit Care. 2020;24:364. doi: 10.1186/s13054-020-03000-7.

62. Schünemann HJ, Cushman M, Burnett AE, Kahn SR, Beyer-Westendorf J, Spencer FA, et al. American Society of Hematology 2018 guidelines for management of venous thromboembolism: prophylaxis for hospitalized and non-hospitalized medical patients. Blood Adv. 2018;2(22):3198-225. doi: https://doi.org/10.1182/bloodadvances.2018022954.

63. Mehta P, Mcauley DF, Brown M, Sanchez E, Tattersall RS, Manson JJ, et al. Correspondence COVID-19: consider cytokine storm syndromes and immunosuppression. Lancet. 2020;6736(20):19-20. doi: 10.1016/S0140-6736(20)30628-0.

64. Murthy S, Gomersall CD, Fowler RA. Care for Critically Ill Patients With COVID-19. JAMA. 2020;323(15):1499-1500. doi: 10.1001/jama.2020.3633.

65. Qin C, Zhou L, Hu Z, Zhang S, Yang S, Tao Y, et al. Dysregulation of immune response in patients with COVID-19 in Wuhan, China. Clin Infect Dis. 2020;71(15):762-8. doi: 10.1093/ $\mathrm{cid} / \mathrm{ciaa} 248$.
66. Mehta P, McAuley DF, Brown M, Sanchez E, Tattersall RS, Manson JJ. COVID-19: consider cytokine storm syndromes and immunosuppression. Lancet. 2020;395(10229):1033-4. doi: 10.1016/S0140-6736(20)30628-0.

67. Ramos-Casals M, Brito-Zerón P, López-Guillermo A, Khamashta MA, Bosch X. Adult haemophagocytic syndrome. Lancet. 2014;383(9927):1503-16. doi: 10.1016/S01406736(13)61048-X.

68. Fardet L, Galicier L, Lambotte O, Marzac C, Aumont C, Chahwan D, et al. Development and validation of the HScore, a score for the diagnosis of reactive hemophagocytic syndrome. Arthritis Rheumatol. 2014;66(9):2613-20. doi: 10.1002/ art.38690.

69. So LK, Lau AC, Yam LY, Cheung TM, Poon E, Yung RW, et al. Development of a standard treatment protocol for severe acute respiratory syndrome. Lancet. 2003;361(9369):1615-7. doi: 10.1016/s0140-6736(03)13265-5.

70. Stockman LJ, Bellamy R, Garner P. SARS: systematic review of treatment effects. PLoS Med. 2006;3(9):e343. doi: 10.1371/journal.pmed.0030343.

71. Tsai MJ, Yang KY, Chan MC, Kao KC, Wang HC, Perng WC, et al. Impact of corticosteroid treatment on clinical outcomes of influenza-associated ARDS: a nationwide multicenter study. Ann Intensive Care. 2020;10(1):26. doi: 10.1186/s13613020-0642-4.

72. Lansbury L, Rodrigo C, Leonardi-Bee J, Nguyen-Van-Tam J, Lim WS. Corticosteroids as adjunctive therapy in the treatment of influenza. Cochrane Database Syst Rev. 2020;48(2):e98e106. doi: 10.1097/ccm.0000000000004093.

73. Rodrigo C, Leonardi-Bee J, Nguyen-Van-Tam J, Lim WS. Corticosteroids as adjunctive therapy in the treatment of influenza. Cochrane Database Syst Rev. 2016;3:CD010406. doi: 10.1002/14651858.CD010406.pub2.

74. Wang Y, Jiang W, He Q, Wang C, Wang B, Zhou P, et al. Early, low-dose and short-term application of corticosteroid treatment in patients with severe COVID-19 pneumonia: single-center experience from Wuhan, China. medRxiv. 2020. doi: https://doi.org/10.1101/2020.03.06.20032342.

75. Zhou ZG, Xie SM, Zhang J, Zheng F, Jiang DX, Li KY, et al. Short-term moderate-dose corticosteroid plus immunoglobulin effectively reverses COVID-19 patients who have failed low-dose therapy. Preprints. 2020;2020030065. doi: 10.20944/preprints202003.0065.v1.

76. RECOVERY Collaborative Group, Horby P, Lim WS, Emberson JR, Mafham M, Bell JL, et al. Dexamethasone in hospitalized patients with COVID-19 - Preliminary report. N Engl J Med. 2020:NEJMoa2021436. doi: 10.1056/NEJMoa2021436.

77. Marano G, Vaglio S, Pupella S, Facco G, Catalano L, Liumbruno GM, et al. Convalescent plasma: new evidence for an old therapeutic tool? Blood Transfus. 2016;14(2):152-7. doi: 10.2450/2015.0131-15. 
78. Garraud O, Heshmati F, Pozzetto B, Lefrere F, Girot R, Sai1lol A, et al. Plasma therapy against infectious pathogens, as of yesterday, today and tomorrow. Transfus Clin Biol. 2016;23(1):39-44. doi: 10.1016/j.tracli.2015.12.003.

79. McGonagle D, Sharif K, O'Regan A, Bridgewood C. The role of cytokines including interleukin-6 in COVID-19 induced pneumonia and macrophage activation syndrome-like disease. Autoimmun Rev. 2020;19(6):102537. doi: 10.1016/j.autrev.2020.102537.

80. Wan S, Yi Q, Fan S, Lv J, Zhang X, Guo X, et al. Characteristics of lymphocyte subsets and cytokines in peripheral blood of 123 hospitalized patients with 2019 novel coronavirus pneumonia (NCP). MedRxiv. 2020. doi: 10.1101/2020.02.10.20021832.

81. Shen C, Wang Z, Zhao F, Yang Y, Li J, Yuan J, et al. Treatment of 5 critically ill patients with COVID-19 with convalescent plasma. JAMA. 2020;323(16):1582-9. doi: 10.1001/ jama.2020.4783.

82. Duan K, Liu B, Li C, Zhang H, Yu T, Qu J, et al. Effectiveness of convalescent plasma therapy in severe COVID-19 patients. Proc Natl Acad Sci U S A. 2020;117(17):9490-6. doi: 10.1073/pnas.2004168117.

83. U.S. Food and Drug Administration [Internet]. Recommendations for investigational COVID-19 convalescent plasma. 2020. Última visita: 13 de abril de 2020. Disponible en: https:// www.fda.gov/vaccines-blood-biologics/investigational-newdrug-ind-or-device-exemption-ide-process-cber/recommendations-investigational-covid-19-convalescent-plasma

84. Rojas M, Rodríguez Y, Monsalve DM, Acosta-Ampudia Y, Camacho B, Gallo JE, et al. Convalescent plasma in COVID-19: possible mechanisms of action. Autoimmun Rev. 2020;19(7):102554. doi: 10.1016/j.autrev.2020.102554.

85. Singh VK, Mishra A, Singh S, Kumar P, Singh M, Jagannath $\mathrm{C}$, et al. Emerging prevention and treatment strategies to control COVID-19. Pathogens. 2020;9(6):E501. doi: 10.3390/ pathogens9060501.

86. Singer BD, Jain M, Budinger S, Wunderink RG. A call for rational intensive care in the era of COVID-19. Am J Respir Cell Mol Biol. 2020;63(1):132-3. doi: 10.1165/rcmb.2020-0151LE. 